\title{
Aerosol indirect effect on warm clouds over South-East Atlantic, from co-located MODIS and CALIPSO observations
}

\author{
L. Costantino and F.-M. Bréon \\ Laboratoire des Sciences du Climat et de l'Environnement, Unité Mixte de Recherche CEA-CNRS-UVSQ, UMR8212, \\ 91191 Gif sur Yvette, France
}

Correspondence to: L. Costantino (lore.costantino@gmail.com)

Received: 25 April 2012 - Published in Atmos. Chem. Phys. Discuss.: 7 June 2012

Revised: 5 November 2012 - Accepted: 19 November 2012 - Published: 4 January 2013

\begin{abstract}
In this study, we provide a comprehensive analysis of aerosol interaction with warm boundary layer clouds over the South-East Atlantic. We use aerosol and cloud parameters derived from MODIS observations, together with co-located CALIPSO estimates of the layer altitudes, to derive statistical relationships between aerosol concentration and cloud properties. The CALIPSO products are used to differentiate between cases of mixed cloud-aerosol layers from cases where the aerosol is located well-above the cloud top. This technique allows us to obtain more reliable estimates of the aerosol indirect effect than from simple relationships based on vertically integrated measurements of aerosol and cloud properties. Indeed, it permits us to somewhat distinguish the effects of aerosol and meteorology on the clouds, although it is not possible to fully ascertain the relative contribution of each on the derived statistics.

Consistently with the results from previous studies, our statistics clearly show that aerosol affects cloud microphysics, decreasing the Cloud Droplet Radius (CDR). The same data indicate a concomitant strong decrease in cloud Liquid Water Path (LWP), which is inconsistent with the hypothesis of aerosol inhibition of precipitation (Albrecht, 1989). We hypothesise that the observed reduction in LWP is the consequence of dry air entrainment at cloud top. The combined effect of CDR decrease and LWP decrease leads to rather small sensitivity of the Cloud Optical Thickness (COT) to an increase in aerosol concentration. The analysis of MODIS-CALIPSO coincidences also evidences an aerosol enhancement of low cloud cover. Surprisingly, the Cloud Fraction (CLF) response to aerosol invigoration is much stronger when (absorbing) particles are located above cloud top than in cases of physical interaction. This result
\end{abstract}

suggests a relevant aerosol radiative effect on low cloud occurrence: absorbing particles above the cloud top may heat the corresponding atmosphere layer, decrease the vertical temperature gradient, increase the low tropospheric stability and provide favourable conditions for low cloud formation.

We also analyse the impact of anthropogenic aerosols on precipitation, through the statistical analysis of CDR-COT co-variations. A COT value of 10 is found to be the threshold beyond which precipitation is mostly formed, in both clean and polluted environments. For larger COT, polluted clouds show evidence of precipitation suppression.

Results suggest the presence of two competing mechanisms governing LWP response to aerosol invigoration: a drying effect due to aerosol enhanced entrainment of dry air at cloud top (predominant for optically thin clouds) and a moistening effect due to aerosol inhibition of precipitation (predominant for optically thick clouds).

\section{Introduction}

The climate relevance of the anthropogenic aerosol impact on clouds has been documented by the Intergovernmental Panel on Climate Change (IPCC, 2007), which also stresses the large uncertainties both in the competing processes and the quantification of the impact. An increase in particle concentration acting as CCN (Cloud Condensation Nuclei) can enhance Cloud Droplet Number Concentration (CDNC), resulting in a reduction of the mean droplet size. For the same overall amount of liquid water, a cloud made of more numerous smaller droplets reflects more than a cloud with fewer and larger droplets (Twomey, 1974, 1977). Thus, an 
increase in aerosol load can lead to an increase in cloud reflectance, assuming that cloud liquid water content remains unchanged. This process, referred to as "Twomey's effect" or "first Aerosol Indirect Effect" (AIE \#1) may produce a negative radiative forcing and, therefore, a net cooling effect on climate. In addition, a further impact of the aerosol interaction with clouds is derived from the strong reduction of collision-coalescence processes in polluted clouds (smaller droplets) leading to a decrease of precipitation efficiency (Albrecht, 1989). Inhibition of precipitation may increase cloud lifetime and cloud Liquid Water Path (LWP), with a possible further increase in Cloud Optical Thickness (COT) and cloud reflectance. This process is referred to as the "second aerosol indirect effect" (AIE \#2) and may significantly affect cloud cover.

Aerosol impact on cloud microphysics (cloud droplet concentration and size distribution) has been studied since the late 50s. Warner and Twomey (1967) and Warner (1967) reported an increase of CCN number concentration, as a consequence of the incorporation of smoke aerosol from sugar cane fires into clouds, and a decrease of cloud droplet mean radius (potentially impeding the growth of rain drops for coalescence). The aerosol impact on cloud microphysics is now well-established on a global scale through several satellitebased analysis (e.g., Bréon et al. 2002; Feingold et al., 2003; Costantino and Bréon, 2010). However, the response of cloud liquid water to aerosol enhancement is still poorly quantified. A number of studies show a significant positive correlation between liquid water path and CCN (Quaas et al., 2008, 2009; Loeb and Shuster, 2008), some indicate a small, but positive correlation (Nakajima et al., 2001; Sekiguchi et al., 2003), while a few demonstrate a negative correlation (Twohy et al., 2005; Matsui et al., 2006; Lee at al., 2009). The widely varying estimate of the aerosol impact on liquid water path, either positive or negative (Han et al., 2002), may depend on the cloud regime (Lebsock, 2008), on the humidity profile above cloud top (Ackerman et al., 2004) or be mostly driven by local meteorology (Menon et al., 2008). As a consequence, the overall aerosol effect on COT and cloud albedo remains unclear, which results in large uncertainties for the aerosol radiative forcing quantification.

Regarding the aerosol impact on cloud life cycle, a strong positive relationship between Cloud Fraction (CLF) and Aerosol Optical Depth (AOD) was found in several satellitebased analysis (Menon et al., 2008; Quaas et al., 2009, 2010). Many studies (reviewed by Stevens and Feingold, 2009) agree that aerosol optical depth and low cloud incidence correlate well with the same meteorological parameters (surface wind speed, atmospheric moisture, stability, etc.). Local variations of one of these parameters may produce misleading co-variations of aerosol and cloud retrievals. It is then of primary importance (but also very difficult) to untangle the impacts of aerosol and meteorology on cloud parameters, in statistical analysis based on spaceborne observations. In addition, satellite products of aerosol description may be af- fected by the presence of nearby clouds, leading to spurious correlations between aerosol and cloud parameters (Marshak et al., 2008; Wen et al., 2008; Varnai and Marshak, 2009).

\subsection{Purpose and strategy}

Our objective is to use satellite remote-sensing observation from simultaneous MODIS and CALIPSO retrievals of aerosol and cloud properties to provide further observationbased evidence of aerosol-induced effect on microphysics (CDR), optical properties (COT), structure (LWP, CLF) and life cycle (precipitation occurrence) of warm boundary layer clouds. The originality of the work lies in the focus over the South-East Atlantic and the use of CALIPSO data to provide a vertical description of the aerosol and cloud layers, in addition to the horizontal sampling by MODIS. Based on CALIPSO information, the aerosol and cloud layers are assumed to be in direct interaction if their altitudes are very close (within a certain threshold). For such cases, a change in cloud properties with respect to a variation in aerosol concentration is interpreted as the result of an aerosol driven process. On the other hand, if aerosol and cloud layers are well separated, the observed cloud change is considered to be induced by other causes than direct cloud-aerosol interaction. Thus, although the reduced temporal sampling of the satellite data does not allow a causality assessment from the statistics, the analysis of MODIS-CALIPSO coincidences permits us to isolate (to a certain degree) aerosol-induced effects from meteorology. It is then possible to obtain more reliable estimates of aerosol impact on clouds, than when using relationships based only on vertically integrated measurements.

The South-East Atlantic region is particularly well suited to investigate aerosol indirect effects. Large amount of aerosol load, generated by fires in Southern Africa occurring annually (Ichoku et al., 2003; Edwards et al., 2006), are injected into the atmosphere and transported by trade winds over the Atlantic ocean (Labonne et Bréon, 2007), where a semi-permanent low cloud field is present. In the absence of wet scavenging, the aerosol layers can stay suspended in the atmosphere for days and be transported to considerable distances. South-East Atlantic is one specific area where large aerosol loads are transported above the cloud deck, well separated from it. Aerosol released from savanna and cropland fires mostly contains Organic Carbon (OC) with various amounts of Black Carbon (BC, emitted primarily in efficient flaming fires), depending on the particular fuel, oxygen availability and combustion phase (Andreae and Merlet, 2001). It has been shown that a more efficient combustion regime results in higher abundance of oxygen at the surface of soot particles. Even if the mass fraction of oxygen within the particle remains rather low, an increase in soot surface oxidation increases aerosol chemical reactivity in the atmosphere and water uptake (Chughtai et al., 2002; Andreae and Gelencsér, 2006). The inorganic component of biomass burning aerosol is made of some insoluble dust, insoluble ash material and 
soluble salts, while half of the organic matter (the major component) is considered to be water soluble (Reid et al., 2005; Hoffer et al., 2005; Decesari et al., 2006). In conclusion, because of the large fraction of organic and inorganic soluble material, smoke particles can be already activated as CCN immediately over the fire (Andreae and Rosenfeld, 2008).

The effect of physical interaction of biomass burning aerosols with water droplets can be statistically quantified by long-term satellite observations. In addition, as a consequence of its strong sunlight absorbing properties, the aerosol layer may warm the atmosphere above the cloud field, leading to a large change in the atmosphere stability. Finally, if the absorbing aerosol layer tops a cloud or a bright surface, its presence leads to a net positive forcing at the Top Of the Atmosphere (TOA).

In this context, our objective is to attempt a quantification of the various aerosol-cloud interaction processes over the South-East Atlantic, where very specific conditions prevail.

\subsection{Theoretical background}

\subsubsection{Cloud optical properties}

The first aerosol indirect effect can be quantitatively illustrated using the relationship, proposed by Stephens (1978), between two integral variables (cloud optical thickness and liquid water path) and the cloud effective radius, which is the main parameter to describe the microphysical properties of warm clouds

$\mathrm{COT}=\frac{3}{2 \rho_{w}} \frac{\mathrm{LWP}}{\mathrm{CDR}}$

where $\rho_{w}$ is the density of water $\left[1 \mathrm{~g} \mathrm{~cm}^{-3}\right]$ and CDR is defined as the ratio between the third and second moment of the size distribution, $n(r)$, of radius $r$. The relation between the mean volume droplet radius and the effective radius is generally estimated empirically in the form $r_{\mathrm{v}}^{3}=k \times \mathrm{CDR}^{3}$, where $k$ is supposed to vary between 0.8 and 0.9 from clean and polluted clouds (Pawlowska and Brenguier, 2000). According to Platnick and Twomey (1994), the cloud liquid water path can be expressed as a function of the cloud volume mean radius and droplet number concentration $\left(N_{c}\right)$, in the form

$\mathrm{LWP}=\mathrm{LWC} \times H \approx 4 \pi \rho_{\mathrm{W}} H N_{\mathrm{c}} \mathrm{CDR}^{3}$

where LWC $\left[\mathrm{g} \mathrm{m}^{-3}\right.$ ] is the Liquid Water Content, $H$ is the cloud geometrical thickness and $r_{\mathrm{v}}$ has been approximated by CDR.

Numerous analysis (e.g., Twomey, 1984; Kaufman and Fraser, 1997; Nakajima et al., 2001) have shown the following relationship between aerosol number concentration $\left(N_{\mathrm{a}}\right)$ within polluted clouds and cloud droplet concentration

$\delta \log N_{\mathrm{c}}=g \delta \log N_{\mathrm{a}}$

where $g$ is a sensitivity parameter. From aircraft measurements over the ocean and land (Kaufman et al., 1991), $g$ was found to be approximately equal to 0.7 . Similarly, based on AVHRR measurements over the oceans, Nakajima et al., (2001) found a value of 0.5. Equations (2) and (3) yield

$\delta \log \mathrm{LWP}=g \delta \log N_{\mathrm{a}}+3 \delta \log \mathrm{CDR}$

The Aerosol Index (AI), defined as the product of the satellite-derived aerosol optical depth and Angstrom exponent (ANG), is a good proxy to quantify aerosol number concentration (Nakajima et al., 2001). It gives more weight to aerosol fine mode (between the most cloud active particles) than AOD alone. If cloud water amount can be assumed constant, Eq. (4) gives

$\delta \log \mathrm{CDR}=-\frac{g}{3} \delta \log N_{\mathrm{a}}=-0.23 \delta \log \mathrm{AI}$.

This means that a linear relationship is expected between the logarithm of the cloud droplet effective radius and the logarithm of the Aerosol Index, with a slope of -0.23 , or -0.17 using the parametrisation of Nakajima et al. (2001). In the following analysis, the strength of the different aerosol impact on cloud micro and macrophysics will be quantified by the slope value (called "sensitivity") of the log-log scale relationship between a given cloud property and Aerosol Index. According to Eq. (1), the strength of aerosol impact on cloud optical thickness is equal in magnitude, but opposite in sign, than that on cloud droplet size, as proposed by Twomey (1974, 1977).

On the other hand, if the assumption of constant liquid water path does not hold, the response of cloud optical thickness to aerosol increase can be expressed in logarithm form as

$\frac{\delta \log \mathrm{COT}}{\delta \log \mathrm{AI}}=\frac{\delta \log \mathrm{LWP}}{\delta \log \mathrm{AI}}-\frac{\delta \log \mathrm{CDR}}{\delta \log \mathrm{AI}}$.

The strength of aerosol impact on cloud reflectance is then the combination of sensitivity of both the droplet size and cloud water content to the presence of aerosol.

Note that, with the objective of quantifying the aerosol impact on the Earth radiation budget, the COT is the proper proxy as it is well related to the cloud albedo for a given sun zenith angle.

\subsubsection{Relationship between cloud reflectance and particle size, in precipitating and non-precipitating clouds}

Lohmann et al. (2000) used a general circulation model to explain differences in CDR-COT relationship between optically thin and thick clouds, as observed by Austin et al. (1999) off the coast of California, from AVHRR data. They show that precipitation works in the direction of keeping LWP constant with increasing cloud optical thickness (as a precipitating cloud grows, more water is removed through rain). According to Eq. (1), cloud droplet radius will show an inverse dependence on cloud optical thickness for a constant 
LWP, of the form

$\mathrm{CDR} \propto \mathrm{COT}^{-1}$

On the other hand, in case of non-precipitating clouds, no specific assumption is made on LWP. Substituting Eq. (2) into Eq. (1), it follows that

$\mathrm{COT} \approx 2 \pi H N_{\mathrm{c}} \mathrm{CDR}^{2}$.

In case of adiabatic clouds, the liquid water content at altitude $z$ above cloud base, $\operatorname{LWC}(z)$, increases almost linearly with altitude. LWP between cloud base $(c b)$ and cloud top $(c t)$ can be easily calculated as

$\mathrm{LWP}=\int_{Z_{c b}}^{Z_{c t}} \operatorname{LWC}(z) d z=\int_{Z_{c b}}^{Z_{c t}} c_{\mathrm{W}} z d z=\frac{1}{2} c_{\mathrm{W}} H^{2}$

where $c_{\mathrm{w}}\left[\mathrm{g} \mathrm{m}^{-4}\right]$ is the moist adiabatic condensation coefficient. It is almost constant in short stratocumulus clouds with geometrical thickness smaller than $1 \mathrm{~km}$ (Brenguier, 1991), depending slightly on the temperature (ranging between 1 and $2.5 \times 10^{-4} \mathrm{~g} \mathrm{~m}^{-4}$ for temperatures between 0 and $40^{\circ} \mathrm{C}$ ).

If a stratiform boundary layer cloud is not precipitating and not influenced by entrainment, there is ample observational evidence (Pawlowska and Brenguier, 2000) that cloud LWC vertical profile follows the so-called adiabatic cloud model. Putting together Eqs. (2), (8) and (9), the relationship between CDR and COT results

$\mathrm{CDR} \propto \mathrm{COT}^{0.2} N_{\mathrm{c}}^{-0.4}$.

As the adiabatic cloud droplet number concentration $N_{\mathrm{c}}$ is constant in a non-precipitating cloud, the droplet effective radius is expected to be an exponential function of cloud optical thickness, with exponent equal to 0.2. The comparison of Eqs. (7) and (10) leads to the conclusion that the slope of the CDR-COT relationship is positive (resp. negative) for non-precipitating (resp. precipitating) clouds.

\section{Dataset}

Depending on the specific analysis, we use data acquired over whole South-East Atlantic region, within $\left[4^{\circ} \mathrm{N}-30^{\circ} \mathrm{S}\right.$; $\left.14^{\circ} \mathrm{W}-18^{\circ} \mathrm{E}\right]$, or limited to a smaller portion just off the coast of Angola, within $\left[2^{\circ} \mathrm{S}-15^{\circ} \mathrm{S} ; 14^{\circ} \mathrm{W}-18^{\circ} \mathrm{E}\right]$. We used data derived from the MODIS and CALIOP sensors, which are onboard the AQUA and CALIPSO satellites, respectively, both part of the so-called A-Train satellite constellation. They fly in close proximity on the same orbit at $705 \mathrm{~km}$ of altitude, within one to two minutes from each other (Stephens et al., 2002) insuring near-coincident observations.

\subsection{MODIS retrievals}

MODIS aerosol retrieval algorithm over ocean (Tanré et al., 1997; Kaufman et al., 1997; Remer et al., 2009) uses six spectral channels $(0.55,0.66,0.86,1.24,1.64,2.12 \mu \mathrm{m})$. Level 2 (L2) products are organised into $5 \mathrm{~min}$ "granules". Only daytime data are considered for aerosol retrieval and the products are generated at a resolution of $10 \times 10 \mathrm{~km}^{2}$. Kaufman et al. (2005a) provide an in-depth analysis of error estimates over ocean and calculated that cloud contamination causes a maximum error in MODIS AOD equal to $0.02 \pm 0.005$. Note that aerosol retrievals are only possible in case of clear or broken clouds condition, when MODIS can see between adjacent clouds.

MODIS retrievals of cloud effective radius and cloud optical depth L2 products (with a resolution of $1 \times 1 \mathrm{~km}^{2}$ ), are derived using six spectral channels (King et al., 1998) at visible and near infrared wavelengths $(0.66,0.86,1.24,1.64$, $2.12,3.75 \mu \mathrm{m})$. In this range of wavelengths, reflectance decreases when droplet size increases, for a constant cloud optical depth. Non-absorbing channel at $0.86 \mu \mathrm{m}$ (over ocean) is chosen to minimise the surface contribution together with the base radiance at $2.12 \mu \mathrm{m}$ (and eventually at 1.64 and $3.75 \mu \mathrm{m}$ ). Then, the couple of retrieved radiances are compared with a pre-computed Look Up Table (LUT). Bréon et al. (2005) show that, if the cloud cover is $80 \%$ instead of the assumed $100 \%$, an overestimate of the cloud droplet radius up to $2 \mu \mathrm{m}$ is expected, indicating that MODIS cloud retrieval algorithm is very sensitive to cloud heterogeneity. On the other hand, cloud retrievals based on the $0.86 / 2.1 \mu \mathrm{m}$ combination are thought to be little affected by the presence of biomass burning and dust aerosols (Haywood et al., 2004).

Cloud top properties, such as Cloud Top Pressure (CTP), are determined using radiances measured in spectral bands located within the broad $15 \mu \mathrm{m} \mathrm{CO} 2$ absorption region (with a resolution of $5 \times 5 \mathrm{~km}^{2}$ ). The comparison against lidar observations indicate that the accuracy of CTP estimates is about $50 \mathrm{hPa}$ for mono-layer clouds (Menzel et al., 2008; Garay et al., 2008; Harshvardan et al., 2009). However, in case of atmospheric profiles with a strong inversion (e.g., marine stratocumulus areas), MODIS retrieval algorithms can place the cloud layer above the inversion, up to $200 \mathrm{hPa}$ off its true position (1000-3000 m). The Level-2 cloud fraction (at $5 \mathrm{~km}$ resolution) is derived from the $1 \mathrm{~km}$ resolution cloud mask.

All atmospheric products are averaged on a $1 \times 1$ degree grid box (on daily, weekly and monthly time scale), and are known as Level 3, L3, products. The QA "confidence" flag (whose value ranges from 3 to 0 , where 3 means "good" quality and 0 means "bad" quality) is used for weighting L2 product onto a $1^{\circ}$ grid low-resolution product.

In addition to aerosol and clouds, MODIS is able to retrieve fires and other thermal anomalies. MODIS Level 2 Active Fire Product (Giglio et al., 2010), MYD14, provides the 
Table 1. Level 2 product used to characterise cloud and aerosol properties from MODISCALIPSO coincident retrievals.

\begin{tabular}{llll}
\hline Product & Dataset & Horizontal Resolution & Sensor (Satellite) \\
\hline \multirow{2}{*}{$\begin{array}{l}\text { Aerosol (05kmALay) } \\
\text { and cloud (05kmCLay) }\end{array}$} & Number_Layers_Found & $5 \mathrm{~km}$ & CALIOP (CALIPSO) \\
\cline { 2 - 3 } & Layer_Top_Altitude & $5 \mathrm{~km}$ & \\
\cline { 2 - 3 } Aerosol (MYD04_L2.C5) & Layer_Base_Altitude & $5 \mathrm{~km}$ \\
\cline { 2 - 3 } & Effective_Optical_Depth_Best_Ocean $(0.55 \mu \mathrm{m})$ & $10 \mathrm{~km}$ \\
\hline \multirow{3}{*}{ Cloud (MYD06_L2.C5) } & Angstrom_Exponent_1_Ocean $(0.55 / 0.86 \mu \mathrm{m})$ & $10 \mathrm{~km}$ \\
\cline { 2 - 3 } & Cloud_Optical_Thickness & $1 \mathrm{~km}$ \\
\cline { 2 - 3 } & Cloud_Water_Path & $1 \mathrm{~km}$ \\
\cline { 2 - 3 } & Cloud_Effective_Radius & $1 \mathrm{~km}$ \\
\cline { 2 - 3 } & Cloud_Top_Pressure & $5 \mathrm{~km}$ \\
\hline
\end{tabular}

position of active fires (latitude and longitude at centre of fire pixel) with a high spatial resolution of $1 \mathrm{~km}$.

\subsection{CALIOP retrievals}

CALIOP is the first spaceborne lidar optimised for aerosol and cloud measurements. It uses two orthogonally polarized channels at $532 \mathrm{~nm}$ and one at 1064 to measure the total backscattered signal (Winker et al., 2007). Its footprint is very narrow, with a laser pulse diameter of $70 \mathrm{~m}$ on the ground (Khan et al., 2008), with a higher vertical resolution in the lower atmosphere than in and the upper layers, from 30 to $300 \mathrm{~m}$ (Winker et al., 2004). CALIPSO Level-1 products provide vertical profiles of Attenuated Backscatter values, while Level-2 products provide, among others, geophysical products at three different horizontal resolutions for clouds ( $333 \mathrm{~m}, 1 \mathrm{~km}$ and $5 \mathrm{~km})$ and one for aerosol $(5 \mathrm{~km})$.

Despite non-perfect spatial coincidences, Kim et al. (2008) consider both geometrically thin and thick clouds (up to several $\mathrm{km}$ ) and find a general agreement of CALIPSO estimates of cloud and aerosol top and bottom heights with those derived from surface-based lidar observations, within $0.1 \mathrm{~km}$. On the other hand, they show a strong discrepancy in aerosol layer altitudes between ground base and CALIOP lidar, when aerosol is located below thick clouds. In a more recent work, Kim et al. (2011) compared cloud top altitudes retrieved from the Cloud Profiling Radar (CPR, onboard of CloudSat satellite) with those observed by CALIOP. For thick tropospheric clouds, while cloud top altitude retrievals from the two instruments show good agreement with each other, discrepancies arise for cloud base estimates, as a consequence of the strong CALIOP signal attenuation.

As a consequence, and as further discussed in the next section, cases of multilayer clouds and aerosol below cloud will not be considered to avoid the strong uncertainties in
CALIPSO retrievals of aerosol and cloud top and bottom layer altitude in presence of thick clouds.

\subsection{MODIS-CALIPSO coincidences}

Cloud parameters are obtained from MODIS Level 2 cloud product of collection C005 (MYD06 L2.C5) at $1 \mathrm{~km}$ resolution for Cloud Optical Thickness, Cloud Water Path, Cloud Effective Radius and $5 \mathrm{~km}$ resolution for Cloud Top Pressure and Cloud Fraction. Aerosol Effective Optical Depth Best Ocean $(0.55 \mu \mathrm{m})$ and Angstrom Exponent 1 Ocean $(0.55 / 0.86 \mu \mathrm{m})$, from MODIS Level 2 aerosol product of collection C005 (MYD04 L2.C5) at $10 \mathrm{~km}$ resolution, are used to estimate Aerosol Index.

Cloud and aerosol layer altitudes are taken from CALIPSO Level 2 products. We make use of Number Layers Found, Layer Top Altitude and Layer Base Altitude, at $5 \mathrm{~km}$ resolution for both aerosol and clouds. MODIS and CALIPSO datasets are summarised in Table 1.

We use data acquired from June 2006 to December 2010. When CALIPSO detects the presence of mono-layer aerosol and cloud fields, we look for MODIS cloud and aerosol retrievals within a radius of $20 \mathrm{~km}$ from the CALIPSO target. Cases of clear-sky are not considered. Time-coincidence of retrievals is assured by the A-train coordinated orbits of Aqua and CALIPSO. This method is described schematically in Fig. 1.

Aerosol and cloud layers are assumed to be physically interacting when the vertical distance of aerosol bottom altitude from cloud top altitude is smaller than $100 \mathrm{~m}$. Inversely, they are considered "well separated" if this distance is larger than $750 \mathrm{~m}$. Aerosol and cloud layers with distance between 100 and $750 \mathrm{~m}$ are uncertain and excluded from our analysis, as are cases with the aerosol layer underneath the cloud layer.

In order to deal with shallow clouds only, cloud top pressure retrievals smaller than $600 \mathrm{hPa}$ are excluded. In addition, 


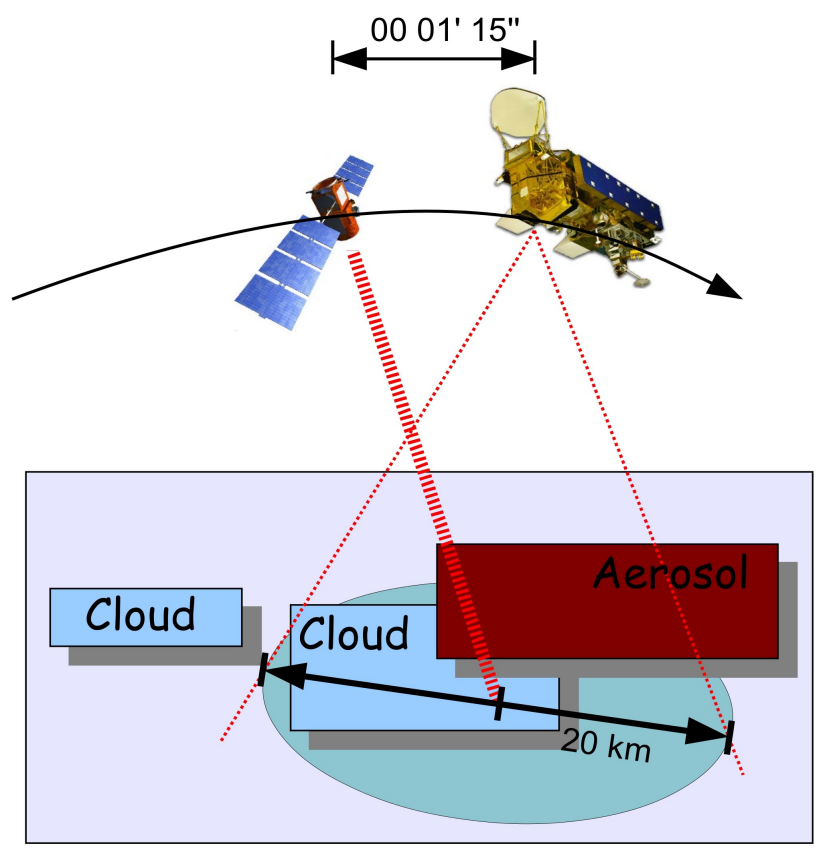

Fig. 1. Scheme of CALIPSO-MODIS coincidence methodology. When CALIPSO detects the presence of single-layer aerosol and cloud fields, we look for MODIS retrievals within a radius of $20 \mathrm{~km}$ from CALIPSO target. The temporal coincidence is insured by the coordinated satellite orbits.

COT smaller than 5 are also excluded because neither a clear distinction between aerosol and clouds, nor an accurate retrieval of cloud properties is reliably possible for optically thin clouds (Nakajima et al., 2001). Finally, cases of multilayer aerosol or clouds (retrievals can be ambiguous in such cases) and aerosol with top layer altitude larger than $10 \mathrm{~km}$ are also excluded. All MODIS retrievals within a $20 \mathrm{~km} \mathrm{ra-}$ dius from the CALIPSO target are averaged together, to provide single estimates of cloud and aerosol parameters for each CALIPSO shot. Cases with average COT larger than 35 and LWP larger than $300 \mathrm{~g} \mathrm{~m}^{-2}$ are excluded to avoid deep convective clouds.

\section{Results}

\subsection{Aerosol production and transport over S-E Atlantic}

We consider four time periods that differ from classical seasons and go from January to March, from April to June, from July to September and from October to December. This particular seasonal choice allows to properly centre the peak of the African Southern Hemisphere dry season biomass burning activity, that mostly occurs from July to September (Ichoku et al., 2000; Myhre et al., 2003; Swap et al., 2003; Eck et al., 2003).

MODIS Level 2 Active Fire Product for 2005 shows that fires over the African continent mainly occur in the respec- tive winter season of each hemisphere (Fig. 2). From November to March, fires are concentrated in the Sahel region, south of the Sahara Desert and north of the Equator, extending approximately from the West coast of Mauritania to Ethiopia (i.e., extending East-West over almost the entire continent). From May to September, fires are mainly located in Southern Africa, covering almost the entire subcontinent, between $0^{\circ} \mathrm{S}$ and $20^{\circ} \mathrm{S}$. In April and October, fires are observed in both regions, north and south of the Equator, but in much smaller numbers. Figure 2 shows seasonal maps of wind speed and direction at 950 and $750 \mathrm{hPa}$ (corresponding approximately at 0.6 and $2.5 \mathrm{~km}$ of altitude) for 2005 , obtained from the monthly averaged data provided by the European Center for Medium-Range Weather Forecasts (ECMWF). Each arrow indicates the direction and intensity of the mean wind at that point. Wind speed is expressed in degrees per day so that arrow's length represents the distance travelled by the air in $24 \mathrm{~h}$. Low level winds at $950 \mathrm{hPa}$ (green arrows), over South-East Atlantic between $0^{\circ} \mathrm{S}$ and $60^{\circ} \mathrm{S}$, show a N-NW circulation. During April-June and July-September, oceanic air masses from the south penetrate into the inner continent (over the Sahel region), while the wind field is particularly weak in Southern Africa. On the other hand, during JanuaryMarch and October-December, the Gulf of Guinea becomes a convergence zone between the northward wind flow from South-East Atlantic and the southward flow from Sahel. At pressure levels of 850 (not shown in the figure) and $750 \mathrm{hPa}$ (red arrows), winds of the Northern Hemisphere (between $20^{\circ} \mathrm{N}$ and $0^{\circ} \mathrm{N}$ ) turn $\mathrm{W}-\mathrm{SW}$, while those of the Southern Hemisphere (between $0^{\circ} \mathrm{S}$ and $20^{\circ} \mathrm{S}$ ) turn W-NW. During April-June and July-September, the wind speed over Southern Africa increases consistently. Coincidently with the peak of fire occurrence (the so called biomass burning season), a strong easterly air transport from the inner continent over ocean is established. In the Northern Hemisphere, air masses from the Sahel are advected westward and southward over the Central Atlantic ocean and the Gulf of Guinea.

From this analysis, one may conclude that, during the winter fire season, the transport of biomass burning aerosol to the Gulf of Guinea is limited and mostly westward, only if the aerosol reaches a sufficient altitude. During the summer season, biomass burning aerosols from Southern Africa are transported efficiently towards the West, but not in the low atmospheric layers. Nevertheless, this analysis is based on seasonal averages and does not exclude different transports, when the wind field does not follow the mean circulation. Another smoke transport mechanism has been observed by Haywood et al. (2008), analysing data from the DABEX (Dust And Biomass-burning Experiment) field campaign. Over West Africa, mineral dust is transported southward from the Sahara Desert (where a strong static stability prevent dust from mixing vertically and trap aerosol in a layer between 900 and $850 \mathrm{hPa}$ ), while biomass burning particles from savanna burning are subjected to a northward advection. When the two flows come into contact (over the convergence 


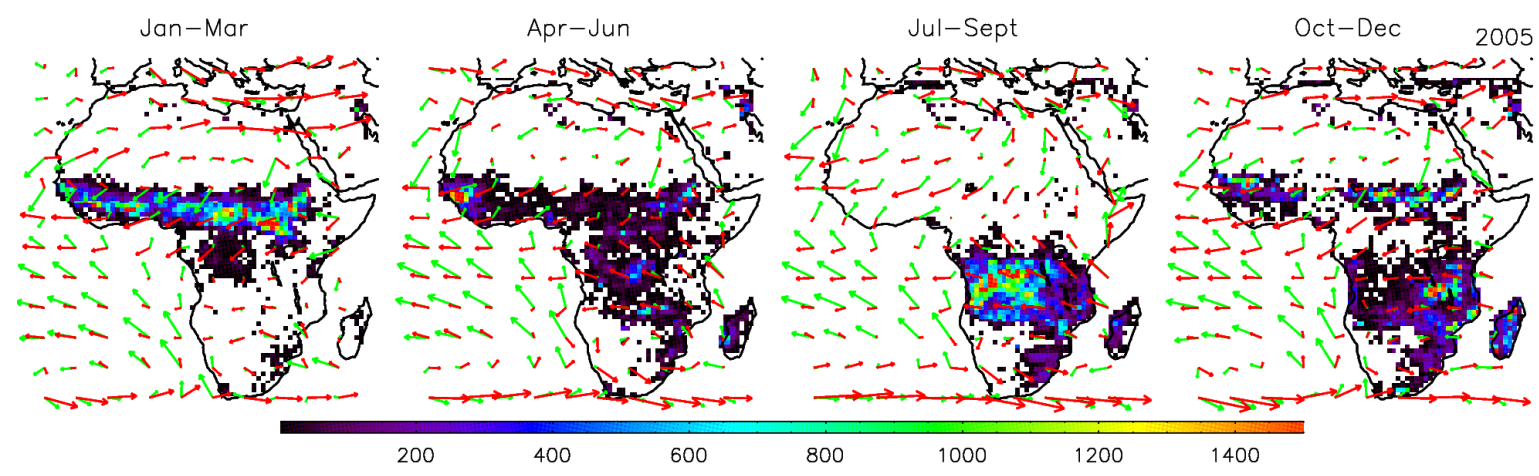

Fig. 2. Maps of fire occurrence for 2005, according to MODIS Active Fire Product. Colour-scale represents the number of active fires detected during each time period, at a nominal resolution (at nadir) of $1 \mathrm{~km}$, within a $1^{\circ} \times 1^{\circ}$ grid box. Wind fields at 950 (green) and 750 (red) $\mathrm{hPa}$ (corresponding approximately to $600 \mathrm{~m}$ and $2.5 \mathrm{~km}$ of altitude) for 2005 are over-plotted on the figure. Seasonal wind maps are obtained from monthly averaged data provided by the European Center for Medium-Range Weather Forecasts (ECMWF). Arrows indicate the direction and intensity of the mean wind at that point. Wind speed is expressed in degrees per day so that arrow's length shows the distance travelled by the air in $24 \mathrm{~h}$.

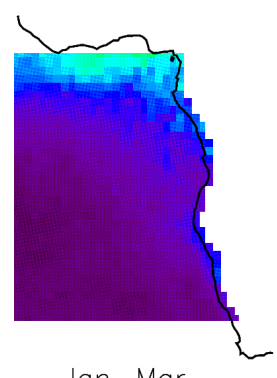

Jan-Mar

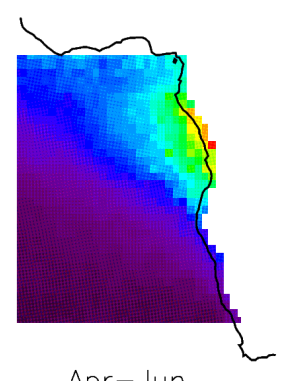

Apr-Jun

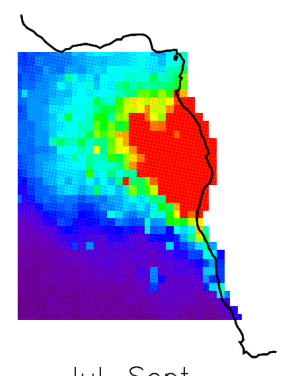

Jul-Sept

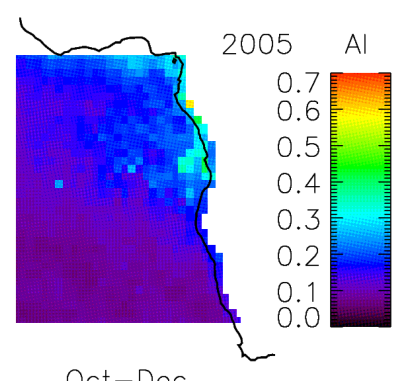

Oct-Dec

Fig. 3. Maps of seasonally averaged measurements of Aerosol Index (AI), for 2005. AI seasonal variability is high, but somewhat different from that of AOD, because aerosol composition and, hence, Angstrom exponent vary during the year.

zone of low level winds, slightly north of $10 \mathrm{~N}$ ), the hotter air mass from biomass burning overrides the cooler dust and is lifted to higher altitudes. With decreasing pressure level, local wind turns southward and westward, allowing for smoke transport over the Gulf of Guinea.

\subsection{Aerosol distribution}

We make use of MODIS Level 3 aerosol daily product over ocean $\left(1^{\circ}\right.$ resolution) to analyse six years $(2005-2010)$ of "seasonally" averaged maps of vertically integrated aerosol and cloud properties.

Figures 3 and 4 respectively show Aerosol Index (AI) and Angstrom exponent (ANG) maps for 2005. While Aerosol Index is somewhat proportional to aerosol number concentration, ANG (computed from measurements at 550 and $865 \mathrm{~nm}$ ) expresses the spectral dependence of aerosol optical depth and provides additional information on aerosol size (the larger the coefficient, the smaller the particle). An Angstrom exponent larger than 1 indicates a dominance of fine-mode particles (Smirnov, 2002; Queface et al., 2003; Thieuleux, 2005). During January-March, AI reaches its maximum value over a small area in the northern part of the region, where it is smaller than AOD, because the Angstrom exponent is generally lower than one. Over the Gulf of Guinea, Aerosol Index ranges between 0.2 and 0.35, AOD between 0.5 and 0.8 and Angstrom exponent is around 0.5 or lower. Dust transported from the Sahara at relatively high altitude dominates the aerosol load. From April to June, when fires begin to occur in Southern Africa, aerosol load sensibly increases over coastal areas between the Gulf of Guinea and Angola. Aerosol index increases up to 0.5 and Angstrom exponent varies between 0.8 and 1.1, suggesting an easterly transport of smoke particles from Southern Africa over ocean, by trade winds.

The heaviest aerosol concentration is observed during the biomass burning season (July-September), with AI values particularly elevated over a wide area off the coasts of Angola, between 0.5 and 1.5 (saturated in the figure that uses a colour scale maximum of 0.7 ).

Angstrom exponent over the whole region is generally larger than 0.7, exceeding unity (yellow and red points) near and off the coast of Angola. This, most likely, results from the abundant presence of biomass burning particles 


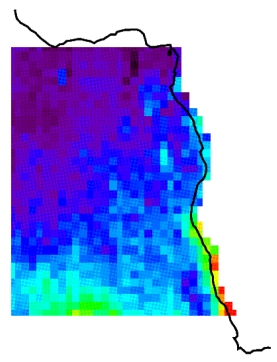

Jan-Mar

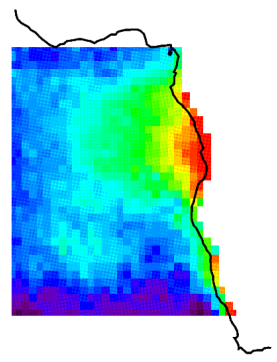

Apr-Jun

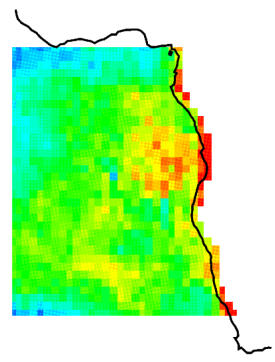

Jul-Sept

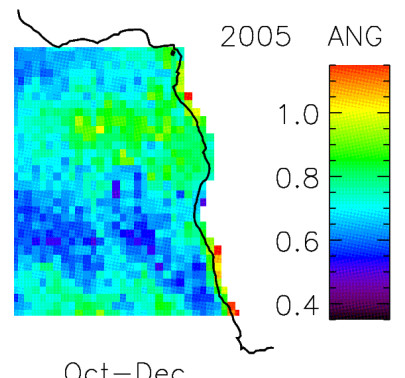

Oct-Dec

Fig. 4. Maps of seasonally averaged measurements of Angstrom exponent (ANG), for 2005.

in the atmosphere. From October, fire occurrence in Southern Africa decreases significantly. Average values of AI and ANG during October-December are much lower than during July-August.

Satellite data for 2006-2010 show a similar annual cycle of aerosol production and transport (with modest interannual variability compared to seasonal variations), dominated by two different regimes. The first one, from October to March, is characterised by optically thin aerosol layers (with AI generally below 0.2) and Angstrom exponents usually smaller than one, indicating the dominance of coarsemode aerosols. The second one, marked by the presence of larger concentrations of smaller particles, begins in April and culminates during the biomass burning season, when $\mathrm{AI}$ and ANG get both larger than one.

\subsection{Aerosol impact on cloud droplet radius}

In Fig. 5 coincident MODIS-CALIPSO estimates of cloud effective radius are averaged over constant bin of AI, from 0.02 to 0.5 (by step of 0.2 ), and reported in log-log scale.

Cases of mixed or nearby aerosol and cloud layers are indicated in red, while case with aerosol above the cloud top are shown in blue. For a total of more than 15000 valid retrievals, $56 \%$ are identified as cases with well-separated layers, while $44 \%$ show close or mixed aerosol and cloud layers. The study area is reduced to the smaller region off the coast of Angola, within $\left[2^{\circ} \mathrm{S}-15^{\circ} \mathrm{S} ; 14^{\circ} \mathrm{W}-18^{\circ} \mathrm{E}\right]$, where a previous analysis indicated that MODIS-CALIPSO coincidences are more homogeneously distributed than over the whole SE Atlantic and statistics are less affected by local variation of meteorological parameters.

Mixed and unmixed case statistics converge to very similar CDR values when aerosol particle concentration is close to zero. With increasing AI, unmixed statistics do not show any significant correlation between changes in Aerosol Index and cloud droplet radius variations. CDR of clouds below the aerosol layer remains almost constant, close to $14-15 \mu \mathrm{m}$ for all aerosol regimes. On the other hand, for mixed cases, CDR decreases by about $30 \%$, from $15-16 \mu \mathrm{m}$ down to $11 \mu \mathrm{m}$, as AI varies from 0.02 to 0.5 .

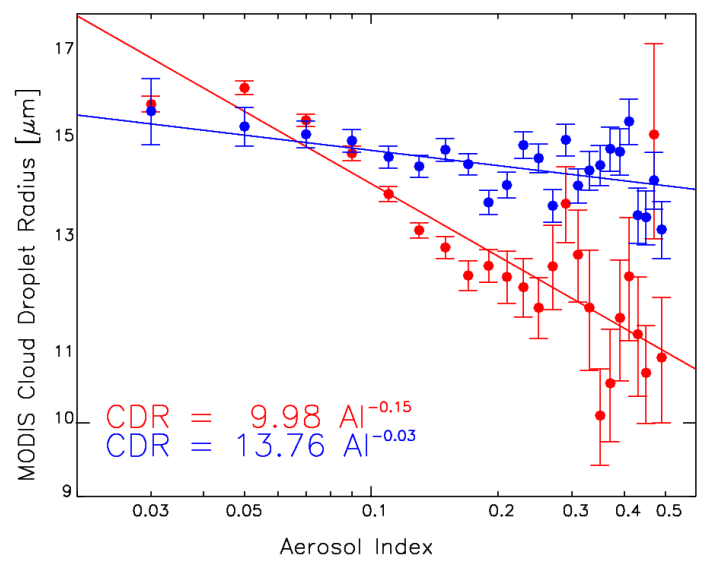

Fig. 5. Cloud Droplet Radius (CDR) retrievals averaged over constant bin of Aerosol Index (AI), in log-log scale, for cases of wellseparated cloud and aerosol layers (blue) and mixed and interacting layers (red), in the region within $\left[2^{\circ} \mathrm{S}-15^{\circ} \mathrm{S} ; 14^{\circ} \mathrm{W}-18^{\circ} \mathrm{E}\right]$. Error bars represent the confidence level of the mean values if one assumes independent data. They are calculated as $\sigma \sigma(n-2)^{1 / 2}$, where $n$ is the number of CDR measurements within the bin and $\sigma \sigma$ is their standard deviation.

The strength of aerosol impact on CDR can be quantified by the linear regression slope of CDR-AI relationship in log-log scale. In good agreement with Twomey's hypothesis, Fig. 5 shows that the logarithmic relationship between $\mathrm{CDR}$ and $\mathrm{AI}$ in case of mixed and interacting layers is close to linear, with a correlation coefficient equal to -0.76 . The strong CDR sensitivity to aerosol increase is expressed by the best-fit slope of -0.15 , five times smaller than in case of unmixed layers $(-0.03)$, and in good agreement with the expected value (between -0.23 and -0.17 ).

\subsection{Aerosol impact on cloud liquid water path}

Averaging coincident MODIS-CALIPSO retrievals of liquid water path, within $\left[2^{\circ} \mathrm{S}-15^{\circ} \mathrm{S} ; 14^{\circ} \mathrm{W}-18^{\circ} \mathrm{E}\right]$, over constant bin of Aerosol Index, LWP-AI relationship (Fig. 6) is somewhat similar to CDR-AI. In case of mixed layers, LWP is decreased by $37 \%$ (from 95 to $60 \mathrm{~g} \mathrm{~m}^{-2}$ ) as AI increases from 0.03 to 0.5 . The resulting linear slope in log-log scale is 


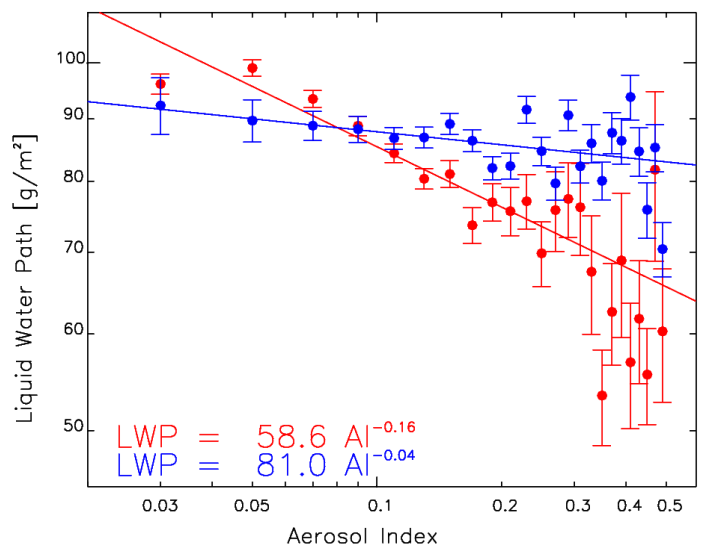

Fig. 6. Liquid Water Path (LWP) retrievals averaged over constant bin of Aerosol Index (AI), in log-log scale, for cases of well separated (blue) and interacting (red) cloud-aerosol layers, in the region within $\left[2^{\circ} \mathrm{S}-15^{\circ} \mathrm{S} ; 14^{\circ} \mathrm{W}-18^{\circ} \mathrm{E}\right]$. The error bars indicate the statistical uncertainties as in Fig. 5.

equal to -0.16. Otherwise, when the aerosol is located above cloud deck, LWP does not show any sensible dependence on aerosol concentration. Cloud water amount remains almost constant at approximately $80-90 \mathrm{~g} \mathrm{~m}^{-2}$ for all aerosol regimes and the resulting best linear fit slope is equal to -0.04 .

In good agreement with expectation, mixed and unmixed layer relationships converge to a same LWP value (within statistical uncertainties), when AI decreases to very small values. We do not get the same result for the whole SouthEast Atlantic region, within $\left[4^{\circ} \mathrm{N}-30^{\circ} \mathrm{S} ; 14^{\circ} \mathrm{W}-18^{\circ} \mathrm{E}\right]$. In the latter case, mixed statistics show that LWP would increase up to $110 \mathrm{~g} \mathrm{~m}^{-2}$ for AI approaching to zero (while unmixed LWP would remain almost unchanged).

\subsection{Aerosol impact on cloud optical thickness}

In Fig. 7, coincident MODIS-CALIPSO estimates of cloud effective radius are averaged over constant bin of AI, from 0.02 to 0.5 (by step of 0.2 ), and reported in log-log scale.

Both for mixed and unmixed cases, COT is little dependent on the Aerosol Index and shows variations that are not a clear function of the AI. A best fit among the rather scattered datapoints indicates that COT varies in average between 8.5 and 9.0. For AI values higher than 0.2, larger error bars indicate stronger statistical uncertainties than in case of lower aerosol loads, due to fewer measurements in the corresponding bin.

The low COT sensitivity to aerosol increase is significantly quantified by the log-log scale linear regression slope. When cloud and aerosol are mixed and interacting, the slope is particularly small, even slightly negative, equal to -0.02 . The large statistical uncertainty in the slope value, equal to \pm 0.06 , and the modest linear correlation coefficient $r=$ -0.47 stress the large variability of COT and its little linear dependence on AI.

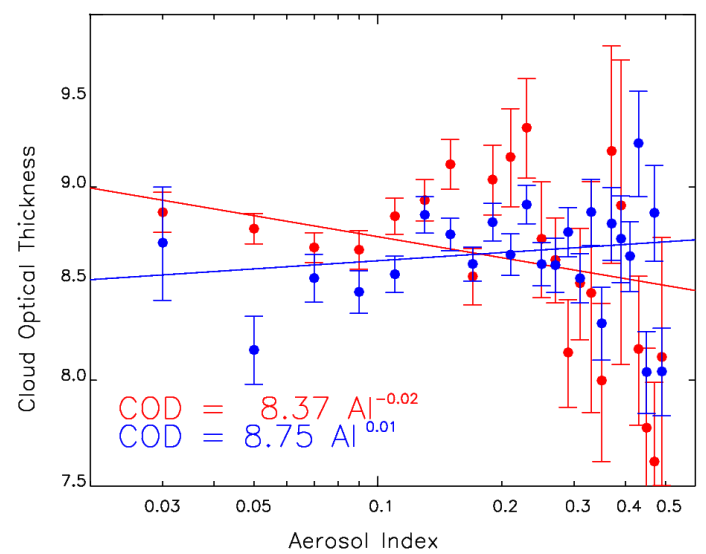

Fig. 7. Cloud Optical Thickness (COT) retrievals averaged over constant bin of Aerosol Index (AI), in log-log scale, for cases of well separated (blue) and mixed (red) cloud-aerosol layers, in the region within $\left[2^{\circ} \mathrm{S}-15^{\circ} \mathrm{S} ; 14^{\circ} \mathrm{W}-18^{\circ} \mathrm{E}\right]$. The error bars indicate the statistical uncertainties as in Fig. 5.

When aerosol and cloud layers are well separated, linear slope is very small and equal to 0.01 (with statistical error of \pm 0.04 and linear regression coefficient $r=0.1$ ).

These results indicate that the impact of aerosol on the cloud optical thickness is hardly distinguishable from the noise.

\subsection{Aerosol impact on cloud fraction}

The cloud lifetime question is complex, and none of the hypothesis discussed in recent literature can uniquely explain the strong positive CLF-AI relationship, generally observed in satellite-derived relationships. As discussed above, the present analysis focuses on a specific area, that is unique by the presence of a layer of low clouds, often topped by large loads of biomass burning aerosols. We use MODIS Level 3 daily product (1 degree resolution) to compute linear regression of log-log scale CLF-AI relationship from 2005 to 2010. Resulting slopes are equal to $0.30-0.32$, in good agreement with the satellite based results of Menon et al. (2008) and Quaas et al. (2009), but overestimating the values obtained from model simulation. For this mono-satellite analysis of cloud-aerosol relationship, where no distinction is made between mixed and unmixed statistics, we make use of MODIS retrievals acquired over the whole South-East Atlantic region, $\left[4^{\circ} \mathrm{N}-30^{\circ} \mathrm{S} ; 14^{\circ} \mathrm{W}-18^{\circ} \mathrm{E}\right]$.

Figure 8 shows cloud fraction estimates averaged over constant bin of cloud top pressure, from MODIS L3 daily product. The data are sorted from clean to polluted into six samples based on the AI by step of 0.05 . The mean AI value of each subset is reported in the figure, indicated with the same colour of the respective symbols. CLF correlates well with cloud top pressure, which is a proxy to roughly estimate cloud vertical development. Lower top pressure indicates 


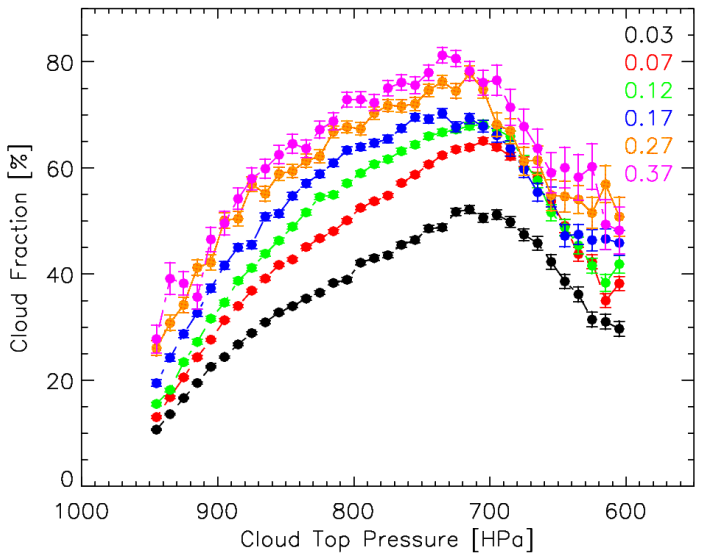

Fig. 8. CLF-CTP relationships from MODIS daily products, at 1 degree resolution, in the region within $\left[4^{\circ} \mathrm{N}-30^{\circ} \mathrm{S} ; 14^{\circ} \mathrm{W}-18^{\circ} \mathrm{E}\right]$. The whole 2005-2010 dataset is sorted by AI, from little to high polluted atmosphere, by step of 0.1 . Colours represent different Aerosol Index intervals (mean AI values are reported in figure). The error bars indicate the statistical uncertainties as in Fig. 5.

taller clouds that reach higher level of the atmosphere. Up to $700 \mathrm{hPa}$, the tallest clouds are characterised by the largest horizontal extension for all aerosol regimes. The results show a boomerang shape of CLF-CTP relationship, with a maximum at approximately $700 \mathrm{hPa}$. The diminution of cloud coverage for CTP larger than $700 \mathrm{hPa}$ may indicate the occurrence of "high" clouds with larger cloud base altitude (in that case CTP is no more representative of cloud vertical extension) or multilayer cloud conditions (in that case the CTPCLF relationship has to be considered meaningless).

Note, however, that higher aerosol concentrations are characterised by larger cloud coverages at every pressure level.

On the other hand, CTP does not show any significant dependence on AI, if CLF is held constant. Figure 9 shows that CTP variations, averaged over constant bin of CLF, are very limited as AI varies between 0.03 and 0.37 . For CLF larger than $60 \%$, they fall within the 2005-2010 annual variability. Slightly larger CTP variations, with increasing AI, are observed for $\mathrm{CLF}<60 \%$. In that case, larger error bars indicate fewer retrievals and averages with smaller representivity. For constant values of CLF, higher aerosol concentrations are not always associated with smaller top pressure, suggesting that CTP variations are not induced by aerosol-cloud interaction. In the hypothesis that aerosol does affect cloud structure, the results indicate that its primary effect is to increase the horizontal extension rather than produce taller and more convective clouds.

In an attempt to isolate aerosol-induced from meteorological effects, we now analyse CLF-AI statistics from mixed (interacting) and well-separated (not interacting) cloud-aerosol layers.

As shown from MODIS observations, larger CTP implies in average larger CLF, as well as larger CLF implies larger

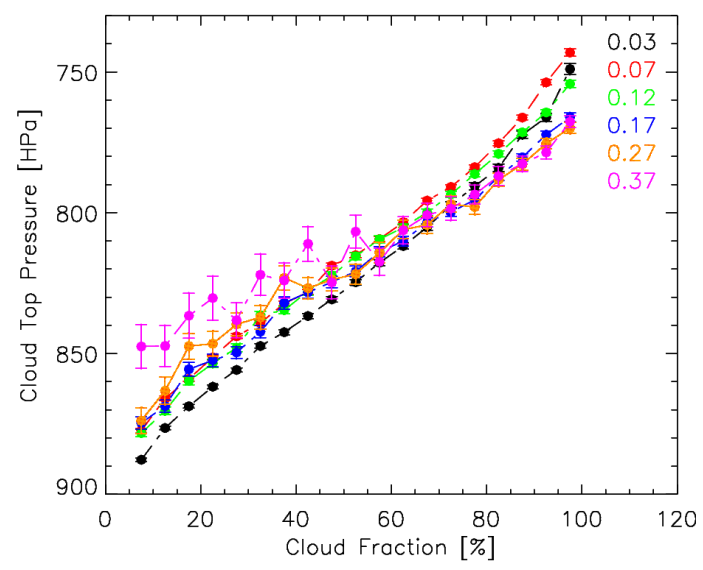

Fig. 9. CTP-CLF relationships from MODIS daily products, at 1 degree resolution, in the region within $\left[4^{\circ} \mathrm{N}-30^{\circ} \mathrm{S} ; 14^{\circ} \mathrm{W}-18^{\circ} \mathrm{E}\right]$. The whole 2005-2010 dataset is sorted by AI, from little to highly polluted atmosphere, by step of 0.1 . Colours represent different Aerosol Index intervals (mean AI values are reported in figure). The error bars indicate the statistical uncertainties as in Fig. 5.

CTP, at least up to $700 \mathrm{hPa}$. We then argue it is better to compare CLF responses of clouds with similar vertical development. Cloud top pressure was found to be rather independent from aerosol interaction with cloud (Fig. 9). Keeping it constant, we minimise CLF variations caused by considering clouds with largely different CTP (due to different local meteorological conditions), without losing any significant information on the strength of aerosol effect.

According to these considerations, mixed and unmixed MODIS-CALIPSO coincidences are sorted by CTP from low to high clouds, by step of $10 \mathrm{hPa}$, to provide a more accurate description of mixed and unmixed CLF sensitivity variation with cloud top pressure. CLF retrievals of each subset are averaged over constant bin of AI (from 0 to 0.7 ) by step of 0.2. The linear regression slope of each CLF-AI relationship in log-log scale is calculated and plotted as a function of the correspondent CTP interval. This process is performed twice, once for the mixed (red) and once the unmixed case (blue), as shown in Fig. 10.

We make use of data from the whole South-East Atlantic $\left[4^{\circ} \mathrm{N}-30^{\circ} \mathrm{S} ; 14^{\circ} \mathrm{W}-18^{\circ} \mathrm{E}\right]$, including those regions excluded in previous analysis. That is because the CTP sorting allows minimising the effect of spatial heterogeneity of local meteorology on CLF-AI co-variation. Note that high clouds generally show a large cover fraction (almost equal to $100 \%$ even at very low AI) that would obviously results in CLF-AI slopes equal to zero. Only cases with CLF lower than $97 \%$ for $\mathrm{AI}=0.01$ are then considered.

We define the sensitivity $(S)$ to aerosol increase, of the cloud parameter $k$, as

$S(k)=\frac{\delta \log k}{\delta \log \mathrm{AI}}$. 


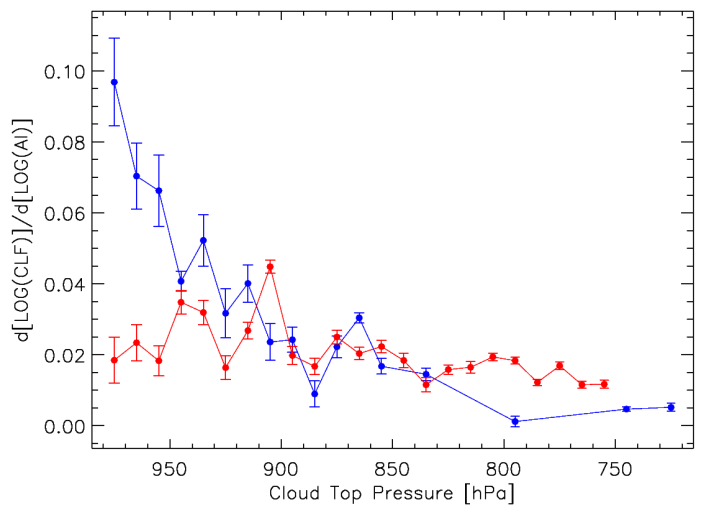

Fig. 10. Cloud fraction sensitivity (i.e., the computed linear regression slope of CLF-AI relationship in log-log scale) as a function of Cloud Top Pressure (CTP), for cases of mixed (red) and well separated (blue) cloud-aerosol layers, in the region within $\left[4^{\circ} \mathrm{N}-30^{\circ} \mathrm{S}\right.$; $\left.14^{\circ} \mathrm{W}-18^{\circ} \mathrm{E}\right]$. The error bars indicate the statistical uncertainties as in Fig. 5.

In case of mixed and interacting layers, cloud fraction sensitivity is small but positive, with no specific dependence on CTP. The error bars indicate the statistical uncertainties, as in Fig. 5. Apart from a few points for CTP between 950 and $900 \mathrm{hPa}, S(\mathrm{CLF})$ varies between 0.025 and 0.015 with an average value of 0.020 .

In case of unmixed layers, CLF sensitivity variations with CTP are compelling. $S(\mathrm{CLF})$ is almost zero when top layer altitude is larger than $2 \mathrm{~km}(\mathrm{CTP}<800 \mathrm{hPa})$. As cloud top pressure exceeds $800 \mathrm{hPa}$, however, CLF dependence on AI becomes positive. $S$ (CLF) undergoes a dramatic increase positively related to cloud top altitude diminution. In case of very low clouds $(\mathrm{CTP}=970 \mathrm{~Pa}), \mathrm{CLF}$ sensitivity reaches a maximum value of 0.10 , five times larger than that observed in mixed statistics for similar top pressure levels.

\subsection{Aerosol impact on precipitation}

To observe the effect of aerosol-cloud interaction on precipitation, we compare the CDR-COT relationship of mixed and unmixed cloud-aerosol layers. Cases of aerosol above cloud top are considered representative of clean cloud properties. In case of cloud-aerosol interaction, we only select data with AI larger than 0.09 to avoid very low aerosol regimes (when CDR values of interacting layers converge to those of unmixed ones) and consider mixed statistics as representative of polluted cloud properties.

In addition, for $\mathrm{AI}>0.09$, mixed and unmixed retrieval number concentrations are very similar over S-E Atlantic. This spatial homogeneity allows to consider all MODIS and CALIPSO coincidences retrieved over the whole region, within $\left[4^{\circ} \mathrm{N}-30^{\circ} \mathrm{S} ; 14^{\circ} \mathrm{W}-18^{\circ} \mathrm{E}\right]$. Figure 11 shows cloud droplet effective radius estimates averaged over constant bin of cloud optical thickness, for clean (blue) and polluted clouds (red). In case of thin clouds (COT $<10$ ), the ex-

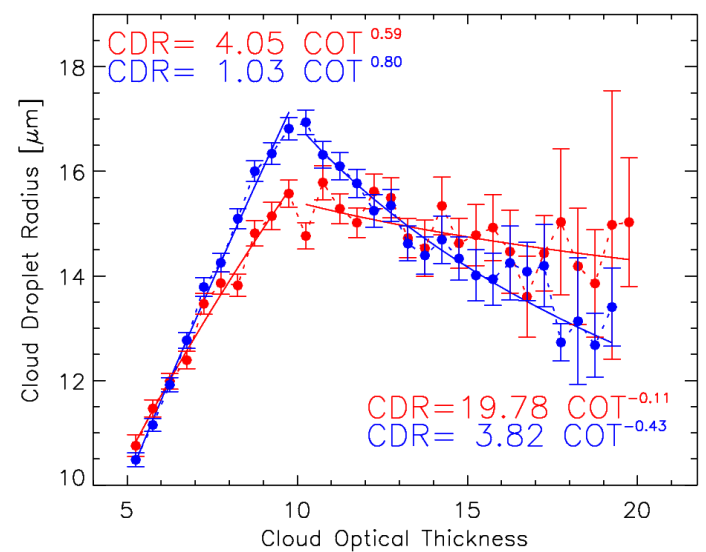

Fig. 11. Cloud Droplet effective Radius (CDR) retrievals averaged over constant bin of Cloud Optical Thickness (COT), for cases of mixed (red) and unmixed (blue) cloud-aerosol layers. Data are representative of low clouds (top pressure lower than $600 \mathrm{hPa}$ ) over South-East Atlantic, within $\left[4^{\circ} \mathrm{N}-30^{\circ} \mathrm{N} ;-14^{\circ} \mathrm{E}-18^{\circ} \mathrm{E}\right]$. Note that in case of mixed layers, only retrievals with $\mathrm{AI}>0.09$ have been selected (polluted clouds). The error bars indicate the statistical uncertainties as in Fig. 5.

ponential fit for clean clouds returns an exponent equal to 0.80 , which is four times larger than the expected value for adiabatic clouds (0.20) and larger than that obtained using MODIS daily retrievals (for the entire 2005-2010 dataset) over the same area (0.14; not shown). Similarly to the clean cloud case, thin polluted clouds show a positive CDR-COT relationship. The exponential fit returns an exponent equal to 0.59 , hardly smaller than in case of well-separated layers. This is consistent with Twomey's effect, according to which the effective radius of polluted droplets is smaller on average than that of unmixed and clean clouds. A cloud optical thickness of approximately 10 defines the threshold value beyond which CDR-COT relationship changes sign, suggesting the occurrence of precipitation in both clean and polluted clouds. For COT between 9 and 11, CDR reaches a maximum value approximately between $17 \mu \mathrm{m}$ (clean clouds) and $15.5 \mu \mathrm{m}$ (polluted clouds), sufficiently large to allow for precipitation production. For a COT of 10 (optically thick clouds), the computed exponent of CDR-COT relationship in case of aerosol above clouds is negative and equal to -0.43 , about half the expected value in case of constant LWP $(-1)$. In case of polluted clouds, the calculated exponent is four times larger than for clean clouds and equal to -0.11 . This means that LWP enhancement with increasing COT is stronger in mixed than in unmixed cases. In the hypothesis that precipitation occurrence reduces the range of variation of liquid water path as cloud optical thickness increases, results may indicate an inhibition of precipitation production as a consequence of aerosol-cloud interaction. 


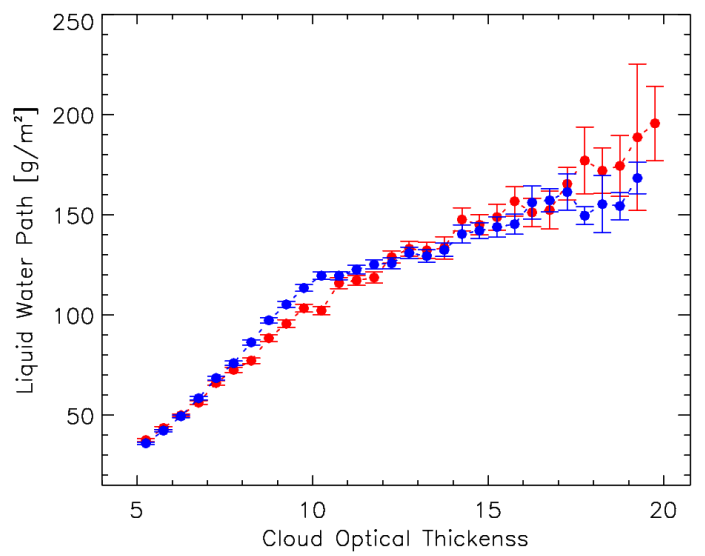

Fig. 12. Liquid Water Path (LWP) retrievals averaged over constant bin of Cloud Optical Thickness (COT). Input data are the same as in Fig. 11.

\section{Error sources and uncertainties}

\subsection{Meteorology}

Figure 13 shows that mixed and unmixed case retrievals are fairly homogeneously distributed over the same area, the central part of South-East Atlantic. We, therefore, argue that these two populations are affected by similar, if not equal, climatological conditions, over the whole time-period. A further check would be the analysis of the data per season, but the relatively low number of MODIS-CALIPSO coincidences does not allow a further binning of the input data. To address this issue, future work should make use of additional, more recent, observations.

On the other hand, the existence of two populations over a given region demonstrates the effect of meteorology and its temporal variability. One shall question whether meteorology, and not aerosol, may explain the observed differences between mixed and unmixed relationships. In the cleanest cases (low AI), however, cloud properties are very similar for both populations. Mixed and unmixed statistics of CDR, LWP, COT and CTP (Fig. 14) converge to the same values (within the statistical uncertainties) with decreasing aerosol concentration. This result has a certain relevance, as it suggests a uniform impact of meteorology on both populations and indicates that changes in cloud properties with increasing AI, when aerosol and clouds intermingle, are most likely to be the result of aerosol-cloud interaction. Cloud top pressure is probably the strongest link to background meteorology. Mixed and unmixed CTP are very similar for low aerosol concentration and this supports the hypothesis that meteorological effect is low. Moreover, as unmixed statistics do not show any significant dependence on aerosol variability, we can also conclude that meteorological effect, if present, is not a function of AI.
One may wonder if cloud microphysical parameters may depend on cloud altitude and, in particular, if the small differences between mixed and unmixed CTP with increasing AI, shown in Fig. 14, can affect CDR and COT (hence LWP) statistics. In a preliminary study, we sorted data by pressure levels and plotted cloud-aerosol relationships as a function of cloud top pressure. Results did not shown any significant difference between resulting CDR and COT sensitivities (almost constant with increasing CTP for both mixed and unmixed cases) and those values presented herein, obtained considering all CTP together. Only CLF-AI relationship has the peculiar dependence on CTP shown in Fig. 10.

\subsection{Absorbing aerosol above cloud top}

Satellite-derived correlations between cloud parameters and aerosol concentration are prone to measurement artifacts and other factors due to systematic errors in satellite retrievals. One may suspect that the presence of absorbing aerosol above the cloud layer can affect MODIS cloud retrievals and create a bias on CDR and COT which depends on aerosol concentration (Wilcox et al., 2009).

Costantino and Breon (2010) analyse the CDR-AI relationship in case of mixed and unmixed case using POLDER estimates of CDR (together with MODIS estimates of AI and the CALIPSO vertical information and aerosol-cloud layer altitude). The POLDER instrument (on board of PARASOL satellite) uses a completely different retrieval technique with respect to MODIS, based on cloud bow analysis by means of polarized radiance measurements (Breon and Doutriaux, 2005). POLDER retrievals of cloud droplet radius, with no identified causes for error, allow for direct comparison with MODIS ones. In both cases of aerosol above and mixed with clouds, they obtain very similar CDR-AI relationships to those shown in Fig. 5 that confirm the reliability of MODIS based statistics of CDR for different aerosol regimes and positions.

For what concerns COT, the work of Haywood et al. (2004) shows that using the $0.86 / 2.1 \mu \mathrm{m}$ combination of wavelengths (that used in this work) the error in COT is minimised, with respect to other MODIS spectral channel. The possibility that absorbing aerosol above clouds can create a negative bias in COT retrievals (and, hence, LWP estimates) is crucial. In the case of mixed cloud and aerosol layers, the screening criteria allow the presence of (at least) part of mixed aerosol layer above cloud top. A decrease in COT with increasing AI due to a MODIS retrieval artifact would mask a possible COT enhancement from Twomey effect and explain the low dependence of COT on AI. In case of aerosol above cloud, however, this MODIS bias would not explain the low COT change with increasing AI. As the Twomey effect is not present, a decrease in COT would be expected as aerosol concentration augments. Thus, comparing mixed and unmixed statistics and inferring aerosol effect by the difference between the two, it seems that MODIS retrieval error 


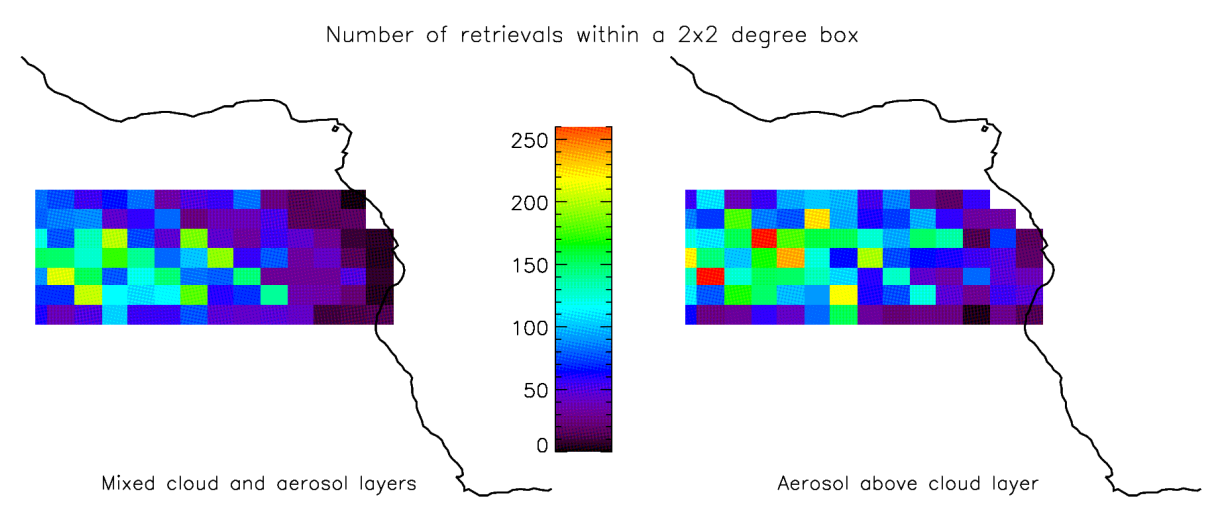

Fig. 13. Number concentration of coincident MODIS-CALIPSO retrievals for all aerosol regimes, in the region within [2S-15S; 14W-18E]. Colour scale represents number of measurements within a $2 \times 2$ degree box, for cases of mixed (left image) and well separated (right image) cloud-aerosol layers.

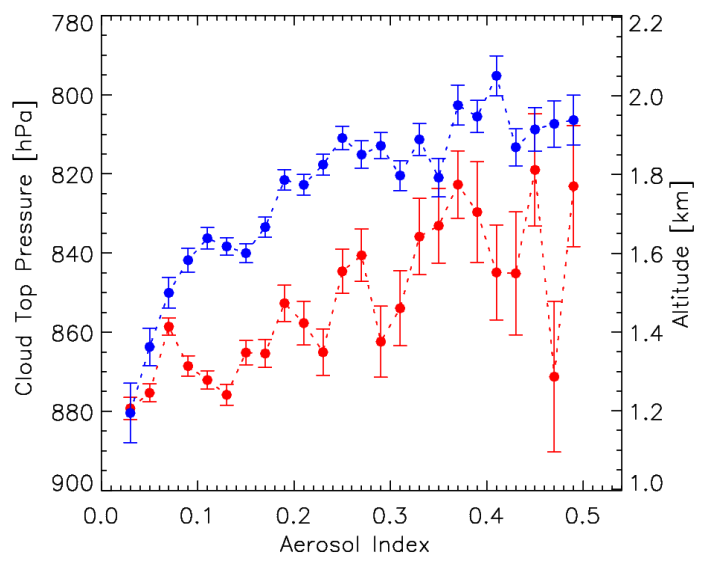

Fig. 14. Cloud Top Pressure (CTP) retrievals averaged over constant bin of Aerosol Index (AI), in linear scale, for cases of well separated (blue) and mixed (red) cloud-aerosol layers, in the region within $\left[2^{\circ} \mathrm{S}-15^{\circ} \mathrm{S} ; 14^{\circ} \mathrm{W}-18^{\circ} \mathrm{E}\right]$. The error bars indicate the statistical uncertainties as in Fig. 5.

due to the presence of absorbing aerosol above clouds is not the leading factor in determining the COT response to AI increase.

\subsection{Error in MODIS estimates of CTP}

As observed in Sect. 2.1, the bias in MODIS retrieved cloud top pressure can be particularly high over those areas characterised by strong temperature inversion, as the study region. In our analysis, however, we account only for relatively low clouds. Cases of MODIS retrievals with top pressure lower than $600 \mathrm{hPa}$ are not considered. We then expect that errors, coming from considering clouds erroneously placed in the elevated layers of the atmosphere up to $1000-3000 \mathrm{~m}$ above their real position, are mostly avoided.

\subsection{Cloud adjacent effect}

A number of works points out another important source of error for MODIS aerosol product, the so called cloud adjacent effect (or "blueing" effect), when cloud-free pixels are brightened (or shadowed) by reflecting light from surroundings clouds. Marshak et al. (2008) found out that enhancement in column radiance is more pronounced at shorter wavelength. Scattered light by clouds in cloud-free pixel is further scattered upward by molecules (Rayleigh scattering) located above cloud top, leading to cloud-induced enhancement of visible reflectance, when aerosol are trapped in the boundary layer (Wen et al., 2008). According to Varnai and Marshak (2009), this effect may lead to significant overestimation of AOD retrievals in cloud-free pixels, as far as $15 \mathrm{~km}$ away from cloud. As it is stronger at shorter wavelengths (where molecular scattering is larger), it can affect the spectral dependence of AOD and lead to increased estimates of Angstrom exponent near cloud edges and a biased high correlation between fine aerosol concentration and cloud fraction.

As CALIPSO retrievals are not expected to be affected by cloud side scattering, we made a short attempt at quantifying the blueing effect, analysing the difference between MODIS and CALIPSO estimates of AOD as a function of the distance between the observed aerosol and cloud layers. One major difficulty is that the MODIS-CALIPSO estimate difference is large and rather variable making an assessment as a function of distance unreliable. Nevertheless, in case of aerosol mixed with clouds, the MODIS-CALIPSO AOD difference shows a very small decrease (of about 0.034 ) as cloud-aerosol pixel distance increases from 2 to $13.5 \mathrm{~km}$ (coherent with the blueing effect), while no significant variation is shown in case of aerosol above cloud top. In our dataset, however, the average distance between coincident aerosol-cloud pixels ranges approximately between 10 and $20 \mathrm{~km}$, which is mostly out of the adjacency effect radius of influence. We then argue that Rayleigh enhancement of MODIS retrieved radiance in 
cloud-free pixel is not expected to be a primary source of error in CLF-AI relationship.

\section{Discussion and interpretation}

\subsection{CDR - AI}

The observed CDR decrease with increasing AI, only in case of mixed layers, is in good agreement with Twomey's theory and suggests a direct modification of cloud microphysics (decrease of the cloud droplet mean size) as a consequence of cloud interaction with aerosol particles, working as $\mathrm{CCN}$. For strong aerosol loads, the mean difference in droplet radius between clean and polluted low clouds over South-East Atlantic is between 3 and $5 \mu \mathrm{m}$.

The spatial distribution of MODIS-CALIPSO coincidence number concentration (Fig. 13) shows that mixed and unmixed case retrievals are mostly concentrated over a similar area. Satellite estimates are then expected to be representative of clouds developed under similar meteorological conditions. According to Sect. 4.1, the observed differences in mixed and unmixed case statistics can be reliably interpreted as resulting from a real aerosol-induced effect, and not from changes in local meteorology. The fact that CDR does not show any sensible evident change with AI increase, when aerosol is located above cloud top, suggests that meteorology (if present) has very little impact on statistics, while aerosol indirect effect is the leading factor in governing the negative CDR-AI relationship, in case of interaction.

\subsection{LWP - AI}

Aerosol interaction with cloud field over South-East Atlantic produces a sensible decrease in cloud liquid water amount which is in clear contrast with the so-called "lifetime effect", proposed by Albrecht in 1989. In a more recent work, however, Ackerman et al. (2004) point out that aerosol-polluted boundary layer clouds are not generally observed to hold more water, but significantly less. They infer that cloud water response to precipitation suppression (due to increased droplet number concentration) is determined by the balance of two competitive factors: (1) moistening, from precipitation decrease, which tends to increase LWP with increasing aerosol concentration; (2) drying, from increasing entrainment of dry overlying air, which tends to decrease LWP. In their model simulation, they find that the entrainment rate $\left[\mathrm{cm} \mathrm{s}^{-1}\right]$ always increases with increasing droplet number concentrations due to Twomey's effect. Only if overlying air is humid or droplet number concentration is very low, surface precipitation reduction is strong enough to dominate LWP response. In conclusion, they identify relative humidity $(\mathrm{RH})$ above boundary layer as the leading factor determining LWP response to changes in droplet concentration. If moisture is high enough, entrainment of air does not result in a dryness of cloud. Relative humidity is presently not detectable from satellites at high vertical resolution. However, the assumptions required by Ackerman's hypothesis are compatible with South-East Atlantic meteorology: during the biomass burning season of Southern Africa, large amount of aerosol particles are transported in elevated atmospheric layers by dry air masses, from inner Southern-Central Africa over ocean. It is reasonable to argue that aerosol-load air is dryer than that just above the inversion (there is no cloud, neither above the continent, nor above the ocean at the aerosol layer altitude). When aerosol mixes with underlying cloud field, increase in cloud droplet number concentration (as a consequence Twomey's effect) may result in the observed LWP reduction of $35 \mathrm{~g} \mathrm{~m}^{-2}$, which is comparable to that estimated by Ackerman et al. (2004) of $25 \mathrm{~g} \mathrm{~m}^{-2}$, for RH of $10 \%$. If aerosol remains high in the atmosphere, well separated from cloud deck, no aerosol-cloud interaction is possible and LWP is expected to remain unaltered. This is in agreement with unmixed LWP trend of Fig. 6, which is very little dependent on aerosol concentration.

There are a number of implications to our findings. First of all, the concept of inhibition of precipitation, commonly related to LWP increase according to the so often invoked Albrecht's hypothesis, can be misleading. The increase of number droplet concentrations and decrease of coalescence efficiency, in clouds polluted by sub-micrometers aerosol, may lead to a large loss of LWP even if surface precipitation is reduced. Under such conditions, COT-AI relationship can be positive or negative, depending on the competitive effect of simultaneous LWP and CDR variations with AI.

\subsection{COT - AI}

Previous results return a log-log scale CDR-AI linear slope, $S(\mathrm{CDR})$, equal to -0.15 and a LWP-AI linear slope, $S$ (LWP), of the same order and equal to -0.16 . Equation (6) shows that the cloud optical thickness response to aerosol enhancement can be estimated as the difference of these two parameters. Hence, in this particular case, no significant COT variations with aerosol enhancement are expected. Averaged values of COT over constant bin of AI, shown in Fig. 7 in $\log -\log$ scale, are consistent with this estimate.

The effect of liquid water path loss compensates the droplet size decrease. This finding has a strong radiative impact. Even if Twomey's hypothesis is valid at a microphysics scale, aerosol-induced droplet size decrease does not produce any significant change in cloud reflectance, as a consequence of LWP loss. Consequently, also the resulting aerosol indirect radiative impact will be rather small.

\subsection{CLF - AI}

Unmixed relationships are supposed to reproduce CLF-AI co-variations induced by other causes than aerosol-cloud interaction, so where do these positive CLF-AI relationships come from? And why are they so strongly related with CTP? 
When aerosol is located above clouds, an increase in low tropospheric stability (LTS) with increasing aerosol concentration would explain the positive CLF sensitivity observed in case of unmixed statistics. Low tropospheric stability is defined as the difference between the potential temperature of the free troposphere $(700 \mathrm{hPa})$ and the surface (Klein and Hartmann, 1993; Klein, 1997; Wood and Hartmann, 2006). The idea that cloud incidence tends to increase with increasing LTS goes back to the beginning of the twentieth century, with the stratocumulus studies of Blake (1928).

In a more recent work, Klein and Hartmann (1993) find a linear relationship between seasonal mean LTS and low cloud amount, for regions in the subtropics.

Aerosol absorption of solar radiation may largely warm lower free troposphere if aerosol resides above cloud cover. Over the Atlantic ocean off the coast of Angola, Wilcox (2009) simulate the radiative effect of an aerosol layer (with single scattering albedo of $0.89 \pm 0.03$ ) distributed between 1.5 and $4.2 \mathrm{~km}$, with a peak at $3 \mathrm{~km}$, and a stratocumulus cloud field (cloud optical thickness of 12) between 0.5 and $1.3 \mathrm{~km}$ (according to a statistics based on CALIPSO retrievals from July to September 2006-2008). For AOD =1, they find a peak heating rate of $3.5 \pm 0.05 \mathrm{~K} \mathrm{day}^{-1}$ at pressure level slightly below $700 \mathrm{hPa}$, about $2.5 \mathrm{~K} \mathrm{day}^{-1}$ larger than in case of no aerosol. In addition, they find that the air temperature at $700 \mathrm{hPa}$ in the case of high smoke load is warmer on average by nearly $1 \mathrm{~K}$, than in the case of low smoke samples.

Unmixed statistics of Fig. 10 shows a positive CLF sensitivity to aerosol increase, smaller for higher cloud top altitudes, but very large in case of shallow clouds. This suggests an aerosol-driven increased inversion strength, more effective at trapping moisture within the boundary layer, as a leading factor in governing the (positive) relationship between low cloud coverage and the concentration of absorbing aerosol above clouds.

However, when aerosol lies within the boundary layer, aerosol warming of air below the inversion is not expected to produce any increase in cloud cover. By means of large eddy simulation of stratocumulus clouds, Johnson et al. (2004) found that aerosol located within well-mixed boundary layer may in turn enhance entrainment of dry air and decrease cloud liquid water path and cloud fraction (semi-direct effect). In case of mixed cloud and aerosol layers, we observe a constant and positive CLF sensitivity (CLF increases with increasing aerosol concentration) as function of CTP (Fig. 10).

Results suggest that even if the aerosol semi-direct effect exists, it is not dominant. Therefore, mixed statistics may reflect the effect of aerosol-cloud microphysical interaction in the way theorised by Albrecht, where precipitation suppression by cloud-active aerosols leads to longer-lived clouds. Note, however, that we do not dispose of observations describing the entire cloud life-cycle and providing the temporal information that would permit a clear distinction between causes and effects. This is to say "cloud lifetime" hypothesis, even if consistent with experimental data, can not be considered as definitive evidence of a certain CLF (and LWP) response to aerosol perturbation.

In case of low clouds, unmixed CLF shows a strong dependence on aerosol concentration that is much larger than that observed for mixed cloud-aerosol layers. This result suggests that the so often invoked "swelling effect" is probably not the main factor governing the observed CLF and AI co-variations. Humidification of aerosol in the vicinity of clouds would induce to retrieve a stronger (at least equal) positive CLF sensitivity when aerosol particles are closer to clouds (mixed condition) and not farther (ummixed condition, with an aerosol-cloud distance threshold of $0.7 \mathrm{~km}$ ). This result is far from being an accurate estimate of the indirect aerosol effect on cloud cover. However, it indicates that if this effect exists, as mixed statistics suggest, its magnitude is just a small fraction of that $0.30-0.32$ value obtained from MODIS daily product, probably dominated by other factors than a true aerosol-cloud microphysical interaction. Among them, the tendency of cloud fraction to correlate with aerosol-driven changes in low tropospheric stability seems to be the main actor.

\subsection{CDR - COT}

For both clean and polluted clouds, the changing sign of the CDR-COT relationship beyond COT $\approx 10$ indicates that precipitation mostly occurs in optically thick clouds, when the average droplet radius attains a critical size between 15.5 and $17 \mu \mathrm{m}$. Examining cloud-precipitation interaction by a combined use of radar and a solar/infrared radiometer on board of TRMM (Tropical Rainfall Measuring Mission), Kobayashi (2007) concludes that the largest effective radius for nonprecipitating cloud is between $15-20 \mu \mathrm{m}$.

The calculated exponential fit for COT $<10$ returns exponential values ( 0.80 for clean and 0.59 for polluted clouds) sensibly larger than expected for adiabatic clouds $(0.20)$ and than observed using MODIS alone (0.14), from L3 daily product over the same area, for 2005-2010 (not shown). The difference between statistics resulting from MODISCALIPSO coincidences (retrieved at $5 \mathrm{~km}$ resolution) and MODIS observations (obtained merging $5 \mathrm{~km}$ onto 1 degree grid box) may indicate that warm clouds differ locally from adiabatic assumption, although the assumption is valid at larger scale.

If we look at LWP as a function of COT in case of optically thin clouds (Fig. 12), cloud water amount increases rapidly with increasing optical thickness. As COT varies between 5 and 10, LWP increases from 40 to $120 \mathrm{~g} \mathrm{~m}^{-2}$ (clean case) and from 40 to $90 \mathrm{~g} \mathrm{~m}^{-2}$ (polluted case). In conclusion, thin liquid clouds over the ocean have in average smaller water amount if they are mixed with polluted atmospheric layers $(\mathrm{AI}>0.09)$. 
For $\mathrm{COT}=10$, the production of large droplets by coalescence-suppression processes is strongly inhibited in polluted environments, so that droplet radius of nonprecipitating clouds is limited at $15.5 \mu \mathrm{m}$. For COT $\approx 10$, the larger exponent of mixed case statistics suggests that polluted clouds rain less than clean ones. As cloud optical thickness increases from 10 to 19 , the liquid water path of clean cloud is increased by $50 \mathrm{~g} \mathrm{~m}^{-2}$ (from 120 to $170 \mathrm{~g} \mathrm{~m}^{-2}$ ), while polluted liquid water by $90 \mathrm{~g} \mathrm{~m}^{-2}$ (from 100 to $190 \mathrm{~g} \mathrm{~m}^{-2}$ ). The percentage difference between clean and polluted LWP increases approximately from -15 to $15 \%$, as COT varies from 10 to 19 . It is equal to zero for COT $\approx 12$.

Results seem to identify the presence of two different regimes. In case of thin clouds, aerosol enhanced entrainment of dry air at cloud top is the main mechanism in determining the LWP response to an increase in aerosol number concentration. This is a clear consequence of the specific meteorology of South-East Atlantic region, where extremely dry air is transported above cloud top, together with aerosol particles. Over other regions, with different humid condition above the inversion, completely different results are expected. In case of thicker clouds, the LWP increase due to aerosol-induced suppression of collision-coalescence processes dominates the water loss due to droplet evaporation at cloud top. If they are thick enough (COT $>12)$, polluted clouds carry more water than clean ones.

\section{Summary and conclusions}

It is always difficult to assess the aerosol impact on cloud and precipitation from statistical analysis of satellite observations as the presence of aerosols correlates strongly with meteorological conditions. As a consequence, it is impossible to fully separate aerosol from meteorological contribution to the observed cloud property variations.

In the present analysis we attempt to reduce this longstanding issue, making use of CALIPSO information to define whether or not aerosol and cloud layers observed by MODIS are mixed and presumably interacting. MODIS and CALIPSO fly in close proximity on the same sunsynchronous orbit and allow for coincident observations of the same Earth target.

We analysed the CDR-AI relationship, showing a decrease in droplet effective radius of mixed case clouds, approximately from 15-16 to $11 \mu \mathrm{m}$, as Aerosol Index varies from 0.02 to 0.5 . When aerosol is located above the cloud top, as it often occurs over South-East Atlantic, effective radius remains almost constant, close to $14-15 \mu \mathrm{m}$. Results are in good agreement with Twomey's hypothesis (Twomey, 1974; Twomey, 1977), according to which fine aerosol particles (efficient $\mathrm{CCN}$ ) may largely increase cloud droplet number concentration. As a consequence, more numerous droplets lead to smaller mean droplet sizes, if cloud water amount remains constant. The fact that unmixed case statistics do not show any consistent correlation between changes in CDR and in AI, confirmed that aerosol-cloud interaction is the leading factor governing the observed cloud response.

Similar to CDR, we also performed statistics of LWPAI and COT-AI, to investigate the response of cloud water amount and optical properties to changes in cloud microphysics. According to Twomey's theory, we expect an increase in cloud optical depth, when mean droplet size drops down (first indirect effect). This is only valid when assuming that the liquid water path is constant.

Contradictory with this hypothesis, coincident MODISCALIPSO observations show a clear decrease in LWP, from $90-100$ to $60 \mathrm{~g} \mathrm{~m}^{-2}$, as AI varies between 0.02 to 0.5 , in case of interaction of cloud and aerosol layers. LWP remains almost constant with increasing AI, when aerosol is above cloud top and cannot interact with the underlying layer. We infer that aerosol-induced LWP diminution is due to the enhancement of dry air entrainment, that leads to droplet evaporation at cloud top. Dry air is presumably transported by trade winds from inner continent over the ocean, together with aerosol particles. In Southern African, absolute humidity can reach extremely low values during the biomass burning season.

Cloud optical thickness response to aerosol enhancement, resulting from the balance of LWP depletion and CDR increase, is very weak in both cases of mixed and unmixed layers.

Although aerosol impact on cloud microphysics is strong, the effect on cloud optical properties is not significant. As a consequence, the first aerosol indirect effect cannot be demonstrated over this particular area. Rather it appears that the very clear impact of aerosol on the cloud microphysics is somewhat compensated by the impact on the cloud liquid water path. To address this issue further, independent measurements of LWP such as those from other instruments of the A-Train (AMSR-E and CLoudsat) would be most useful. Indeed, MODIS algorithm calculates LWP directly from CDR and COT estimates and is, therefore, not independent.

As indicated in Sect. 4.1, to better infer the role of local meteorological conditions, we recommend further work to study the seasonal variability of the observed relations, which we did not performed in part due to the insufficient number of MODIS-CALISPO coincidences. In addition, we believe that sub-sampling each relationships by cloud optical thickness would be an interesting way to analyse the aerosol signature on different cloud types.

The cloud fraction response to aerosol-induced changes in LWP has been investigated from the analysis of CLF-AI relationship. We found that CLF is strongly correlated to cloud top pressure, which is a good proxy to approximately estimate cloud vertical extension. If clouds form under the same quantity of aerosol but different meteorological condition, they would develop differently and present different vertical extensions. 
Since changes in local meteorology can produce spurious correlation between changes in CLF and AI, we decided to minimize the effect of considering clouds under different meteorological conditions sorting data by CTP. In that way, differences between mixed and unmixed case statistics can be reliably attributed to the effect of aerosol-cloud interaction.

In case of mixed layers, we found a positive CLF sensitivity equal to 0.02 , for cloud top altitude at every pressure level. This value is much smaller that those generally found from satellite-based observations (Menon et al., 2008; Quaas et al., 2009). Indeed, when aerosol lies above cloud top, cloud fraction sensitivity is large for lower clouds (up to 0.09 at $\mathrm{CTP}=970 \mathrm{hPa}$ ), decreasing with decreasing CTP (almost zero at $\mathrm{CTP}=750 \mathrm{hPa}$ ). Absorbing particles above cloud top may largely warm the atmosphere and increase the low tropospheric stability. The enhancement of LTS increases the strength of inversion, suppressing cloud vertical extent, maintaining a well-mixed and moist boundary layer and providing favourable condition to the enhancement of low cloud cover over ocean. Aerosol radiative effect is then supposed to be a major driver of cloud fraction increase, in case of unmixed layers.

Aerosol impact on precipitation and cloud life-cycle has been analysed as well. Previous studies (Lohmann et al., 2000) have shown that occurrence of precipitation is detectable by studying the relationship between CDR and COT. A change in the sign of the curve slope can reliably be attributed to the transition from non-precipitating to precipitating clouds. For non-precipitating clouds, CDR is expected to be a positive exponential function of COT. For COT $<10$, the calculated exponent of CDR-COT relationship is equal to 0.59 in case of mixed layers, and equal to 0.80 in case on unmixed, whereas the theoretical value for adiabatic clouds is 0.20 . We then observe that optically thin clouds over SouthEast Atlantic are generally non-precipitating, but showing a certain deviation from the adiabatic assumption, at least at local scale ( $5 \mathrm{~km}$ resolution).

On the other hand, precipitating clouds are expected to show an exponential relationship of CDR as a function of COT, with negative exponent. According to the theory, the more precipitating the cloud the smaller is the exponent. In case of mixed layers, the calculated exponent is -0.11 , while in case of aerosol above clouds the exponent is four times smaller and equal to $-0.43(-0.47$, using MODIS L3 daily product alone). We infer an aerosol-induced effect on precipitation, which is inhibited in polluted clouds. This is expected to be a consequence of collision-coalescence suppression, by aerosol-driven change in cloud microphysics. Smaller droplets convert to rain less efficiently. In conclusion, optically thin clouds carry more water in clean than in polluted environments. As COT goes over 10, clouds begin to precipitate and clean ones precipitate more. As a consequence, more water is removed through rain. Beyond a COT value of approximately 12 , polluted clouds are generally characterised by higher LWP than clean ones. Results are in good agreement with Albrecht's hypothesis (Albrecht, 1989) and LWP response to AI enhancement seems governed by two opposite effects.

The first one is a drying effect due to aerosol-induced enhanced entrainment of dry air at clouds top, that leads to droplet evaporation and is dominant in optically thin clouds. The second one is a moistening effect, due to aerosol decrease of collision-coalescence processes, that leads to precipitation suppression and increased cloud water amount, dominant in optically thicker clouds.

Evidence of the present results shows that aerosol intrusion into low cloud systems can suppress precipitation and lead to longer-lived clouds, stressing a further possible pathway by which human activity is associated to changes in hydrologic cycle and more generally to climate change. Further work is needed to better quantify pollution impact on rain development and, more generally, on low cloud coverage enhancement (with and without physical interaction between aerosol and cloud droplets). In order to address this issue, the use of precipitable water retrievals together with low tropospheric stability estimates and independent measurements of the cloud liquid water content would be a valuable addition to MODIS-CALIPSO statistics.

Acknowledgements. We are grateful to the ICARE centre for providing computing resources and easy access to data, acquired by NASA and CNES satellites.

Edited by: O. Dubovik

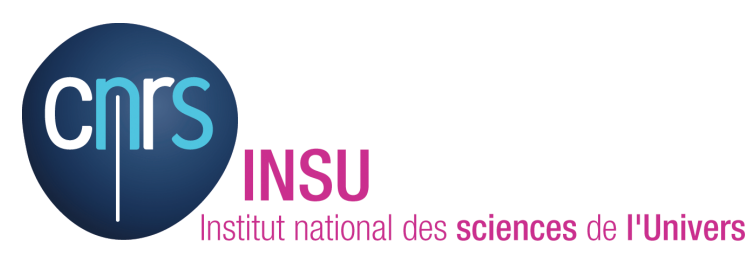

The publication of this article is financed by CNRS-INSU.

\section{References}

Ackerman, A. S., Kirkpatrick, M. P., Stevens, D. E., and Toown, O. B.: The impact of humidity above stratiform clouds on indirect aerosol climate forcing. Nature, 432, 1014-1017, doi:10.1038/nature03174, 2004.

Albrecht, B. A.: Aerosols, Cloud Microphysics, and Fractional Cloudiness. Science, 245, 1227-1230, 1989.

Andreae, M. O. and Gelencsér, A.: Black carbon or brown carbon? The nature of light-absorbing carbonaceous aerosols, Atmos. Chem. Phys., 6, 3131-3148, doi:10.5194/acp-6-3131-2006, 2006.

Andreae, M. O. and Merlet, P... Emission of trace gases and aerosols from biomass burning, Global Biogeochem. Cy., 15, 955-966, 2001. 
Andreae, M. O. and Rosenfeld, D.: Aerosol-cloudprecipitation interactions. Part 1: The nature and sources of cloud-active aerosols, Earth Sci. Rev., 89, 13-41, doi:10.1016/j.earscirev.2008.03.001, 2008.

Austin, P. H., Szczodrak, M., and Lewis, G. M.: Spatial variability of satellite-retrieved optical depth and effective radius in marine stratocumulus clouds, in Proceedings of the 10th Conference on Atmospheric Radiation, Madison, Wisconsin, Amer. Meteorol. Soc., 237-240, 1999.

Brenguier, J. L.: Parameterization of the condensation process: A theoretical approach, J. Atmos. Sci., 48, 264-282, 1991.

Bréon, F. M. and Doutriaux-Boucher, M.: A comparison of cloud droplet radii measured from space, IEEE Trans Geosci. Remote Sens., 43, 1796-1805, 2005.

Bréon, F.-M., Tanré, D., and Generoso, S.: Effect of aerosols on cloud droplet size monitored from satellite, Science, 295, 834838, doi:10.1126/science.1066434, 2002.

Chughtai, A. R., Kim, J. M., and Smith, D. M.: The effect of air/fuel ratio on properties and reactivity of combustion soots, J. Atmos. Chem., 43, 21-43, 2002.

Costantino, L. and Bréon, F.-M.: Analysis of aerosol-cloud interaction from multi-sensor satellite observations, Geophys. Res. Lett., 37, L11801, doi:10.1029/2009GL041828, 2010.

Decesari, S., Fuzzi, S., Facchini, M. C., Mircea, M., Emblico, L., Cavalli, F., Maenhaut, W., Chi, X., Schkolnik, G., Falkovich, A., Rudich, Y., Claeys, M., Pashynska, V., Vas, G., Kourtchev, I., Vermeylen, R., Hoffer, A., Andreae, M. O., Tagliavini, E., Moretti, F., and Artaxo, P.: Characterization of the organic composition of aerosols from Rondonia, Brazil, during the LBASMOCC 2002 experiment and its representation through model compounds, Atmos. Chem. Phys., 6, 375-402, doi:10.5194/acp6-375-2006, 2006.

Edwards, D. P., Emmons, L. K., Gille, J. C., Chu, A., Attie, J. L., Giglio, L., Wood, S. W., Haywood, J., Deeter, M. N., Massie, S. T., Ziskin, D. C., and Drummond, J. R.: Satellite observed pollution from Southern Hemisphere biomass burning, J. Geophys. Res.-Atmos., 111, D14312, doi:10.1029/2005jd006655, 2006.

Eck, T. F., Holben, B. N., Ward, D. E., Mukelabai, M. M., Dubovik, O., Smirnov, A., Schafer, J. S., Hsu, N. C., Piketh, S. J., Queface, A., Le Roux, J., Swap, R. J., and Slutsker, I.: Variability of biomass burning aerosol optical characteristics in southern Africa during the SAFARI 2000 dry season campaign and a comparison of single scattering albedo estimates from radiometric measurements, J. Geophys. Res., 108, 8477, doi:10.1029/2002JD002321, 2003.

Feingold, G., Eberhard, W. L., Veron, D. E., and Previdi, M.: First measurements of the Twomey indirect effect using ground-based remote sensors, Geophys. Res. Lett., 30, 1287, doi:10.1029/2002GL016633, 2003.

Garay, M. J., de Szoeke, S. P., and Moroney, C. M.: Comparison of marine stratocumulus cloud top heights in the southeastern Pacific retrieved from satellites with coincident ship-based observations, J. Geophys. Res., 113, D18204, doi:10.1029/2008JD009975, 2008.

Giglio, L., Descloitres, J., Justice, C. O., and Kaufman, Y.: An enhanced contextual fire detection algorithm for MODIS, Remote Sens. Environ., 87, 273-282. doi:10.1016/S00344257(03)00184-6, 2003.
Han, Q., Rossow, W. B., Zeng, J., and Welch, R.: Three different behaviors of liquid water path of water clouds in aerosol-cloud interactions, 59, 726-735, doi:10.1175/15200469(2002)059<0726:TDBOLW>2.0.CO;2, 2002.

Harshvardhan, Z. G., Di Girolamo, L., and Green, R. N.: Satelliteobserved location of stratocumulus cloudtop heights in the presence of strong inversions. IEEE Trans. Geosci. Remote Sens., 47, doi:10.1109/TGRS.2008, 2005406, 1421-1428, 2009.

Haywood, J. M., Pelon, J., Formenti, P., Bharmal, N., Brooks, M., Capes, G., Chazette, P., Chou, C., Christopher, S., Coe, H., Cuesta, J., Derimian, Y., Desboeufs, K., Greed, G., Harrison, M., Heese, B., Highwood, E. J., Johnson, B., Mallet, M., Marticorena, B., Marsham, J., Milton, S., Myhre, G., Osborne, S. R., Parker, D. J., Rajot, J.-L., Schulz, M., Slingo, A., Tanré, D., and Tulet, P.: Overview of the Dust and Biomass-burning Experiment and African Monsoon Multidisciplinary Analysis Special Observing Period-0, J. Geophys. Res., 113, D00C17, doi:10.1029/2008JD010077, 2008.

Haywood, J. M., Osborne, S. R., and Abel, S. J.: The effect of overlying absorbing aerosol layers on remote sensing retrievals of cloud effective radius and cloud optical depth, Q. J. Roy. Meteorol. Soc., 130, 779-800, 2004.

Hoffer, A., Gelencser, A., Guyon, P., Kiss, G., Schmid, O., Frank, G., Artaxo, P., and Andreae, M. O.: Optical properties of humiclike substances (HULIS) in biomass-burning aerosols, Atmos. Chem. Phys. Discuss., 5, 7341-7360, 2005,

http://www.atmos-chem-phys-discuss.net/5/7341/2005/.

Ichoku, C., Remer, L. A., Kaufman, Y. J., Levy, R., Chu, D. A., Tanré, D., and Holben, B. N.: MODIS observation of aerosols and estimation of aerosol radiative forcing over southern Africa during SAFARI 2000, J. Geophys. Res., 108, 8499, doi:10.1029/2002JD002366, 2003.

Kaufman, Y. J. and Fraser, R. S.: The effect of smoke particles on clouds and climate forcing, Science, 277, 1636-1639, 1997.

Kaufman, Y. J., Fraser, R. S., and Mahoney, R. L.: Fossil fuel and biomass burning effect on climate-Heating or cooling?, J. Clim., 4, 578-588, 1991.

Kaufman, Y. J., Tanré, D., Remer, L. A., Vermote, E. F., Chu, A., and Holben, B. N.: Operational remote sensing of tropospheric aerosol over land from eos moderate resolution imaging spectroradiometer, J. Geophys. Res.-Atmos., 102, 17051-17067, 1997.

Kaufman, Y. J., Remer, L., Tanré, D., Li, R., Kleidman, R., Mattoo, S., Levy, R., Eck, T., Holben, B., Ichoku, C., Martins, J., and Koren, I.: A critical examination of the residual cloud contamination and diurnal sampling effects on MODIS estimates of aerosol over ocean, IEEE Trans. Geosci. Remote Sens., 43, 2886-2897, 2005a.

Kaufman, Y. J., Koren, I., Remer, L. A., Rosenfeld, D., and Rudich, Y.: The effect of smoke, dust and pollution aerosol on shallow cloud development over the Atlantic Ocean, Proc. Natl. Acad. Sci. USA, 102, 11207-11212, doi:10.1073/pnas.0505191102, 2005 b.

Kahn, R. A., Chen, Y., Nelson, D. L., Leung, F.-Y., Li, Q., Diner, D. J., and Logan, J. A.: Wildfire smoke injection heights; two perspectives from space, Geophys. Res. Lett, 35, L04809, doi:10.1029/2007GL032165, 2008.

Kim, S.-W., Berthier, S., Raut, J.-C., Chazette, P., Dulac, F., and Yoon, S.-C.: Validation of aerosol and cloud layer structures from the space-borne lidar CALIOP using a ground-based 
lidar in Seoul, Korea, Atmos. Chem. Phys., 8, 3705-3720, doi:10.5194/acp-8-3705-2008, 2008.

Kim, S.-W., Chung, E.-S., Yoon, S.-C., Sohn, B.-J., and Sugimoto, N.: Intercomparisons of cloud-top and cloud-base heights from ground-based Lidar, CloudSat and CALIPSO measurements, Int. J. Remote Sens., 32, 1179-1197, 2011.

King, M. D., Tsay, S. C., Platnick, S. E., Wang, M., and Liou, K. N.: Cloud retrieval algorithms for MODIS: Optical thickness, effective particle radius, and thermodynamic phase, MODIS Algorithm Theoretical Basis Document, ATBD-MOD-05, 78 pp., 1997.

Labonne, M., Bréon, F.-M., and Chevallier, F.: Injection height of biomass burning aerosols as seen from a spaceborne lidar, Geophys. Res. Lett., 34, L11806, doi:10.1029/2007GL029311, 2007.

Lebsock, M. D., Stephens, G. L., and Kummerow, C.: Multisensor satellite observations of aerosol effects on warm clouds, J. Geophys. Res., 113, D15205, doi:10.1029/2008JD009876, 2008.

Lee, S. S., Penner, J. E., and Saleeby, S. M.: Aerosol effects on liquid-water path of thin stratocumulus clouds, J. Geophys. Res., 114, D07204, doi:10.1029/2008JD010513, 2009.

Loeb, N. G. and Schuster, G. L.: An observational study of the relationship between cloud, aerosol and meteorology in broken low-level cloud conditions, J. Geophys. Res., 113, D14214, doi:10.1029/2007JD009763, 2008.

Lohmann, U., Tselioudis, G., and Tyler, C.: Why is the cloud albedo-particle size relationship different in optically thick and optically thin clouds?, Geophys. Res. Lett., 1099, 1102, doi:10.1029/1999GL011098, 2000.

Marshak, A., Wen, G., Coakley, J., Remer, L., Loeb, N. G., and Cahalan, R. F.: A simple model for the cloud adjacency effect and the apparent bluing of aerosols near clouds J. Geophys. Res., 113, D14S17, doi:10.1029/2007JD009196, 2008.

Matsui, T. and Pielke, Sr., R.: Measurement-based estimation of the spatial gradient of aerosol radiative forcing. Geophys. Res. Lett., 33, L11813, doi:10.1029/2006GL025974, 2006.

Menon, S., Del Genio, A. D., Kaufman, Y., Bennartz, R., Koch, D., Loeb, N., and Orlikowski, D.: Analyzing signatures of aerosolcloud interactions from satellite retrievals and the GISS GCM to constrain the aerosol indirect effect, J. Geophys. Res., 113, D14S22, doi:10.1029/2007JD009442, 2008.

Menzel, W. P., Frey, R. A., Zhang, H., Wylie, D. P., Moeller, C. C., Holz, R. E., Maddux, B., Baum, B. A., Strabala, K. I., and Gumley, L. E.: MODIS global cloud-top pressure and amount estimation: Algorithm description and results, J. Appl. Meteorol. Climatol., 47, 1175-1198, 2008.

Myhre, G., Berntsen, T. K., Haywood, J. M., Sundet, J. K., Holben, B. N., Johnsrud, M., and Stordal, F.: Modelling the solar radiative impact of aerosols from biomass burning during the Southern African Regional Science Initiative (SAFARI-2000) experiment, J. Geophys. Res.,108, 8501, doi:10.1029/2002JD002313, 2003.

Nakajima, T., Higurashi, A., Kawamoto, K., and Penner, J. E.: A possible of correlation between satellite-derived cloud and aerosol microphysical parameters, Geophys. Res. Lett., 28, 1171-1174, 2001.

Pawlowska, H. and Brenguier, J. L.: Microphysical properties of stratocu mulus clouds during ACE-2, Tellus, Ser. B, 52, 867$886,2000$.

Platnick, S. and Twomey, S.: Determining the susceptibility of cloud albedo to changes in droplet concentration with the ad- vanced very high resolution radiometer, J. Appl. Meteorol., 33, 334-347, 1994.

Quaas, J., Ming, Y., Menon, S., Takemura, T., Wang, M., Penner, J. E., Gettelman, A., Lohmann, U., Bellouin, N., Boucher, O., Sayer, A. M., Thomas, G. E., McComiskey, A., Feingold, G., Hoose, C., Kristj 'ansson, J. E., Liu, X., Balkanski, Y., Donner, L. J., Ginoux, P. A., Stier, P., Grandey, B., Feichter, J., Sednev, I., Bauer, S. E., Koch, D., Grainger, R. G., Kirkev ${ }^{\circ} a g$, A., Iversen, T., Seland, Ø., Easter, R., Ghan, S. J., Rasch, P. J., Morrison, H., Lamarque, J.-F., Iacono, M. J., Kinne, S., and Schulz, M.: Aerosol indirect effects - general circulation model intercomparison and evaluation with satellite data, Atmos. Chem. Phys., 9, 8697-8717, doi:10.5194/acp-9-8697-2009, 2009.

Quaas, J., Stevens, B., Stier, P., and Lohmann, U.: Interpreting the cloud cover - aerosol optical depth relationship found in satellite data using the general circulation model, Atmos. Chem. Phys., 6129-6135. doi:10.5194/acp-10-6129-2010, 2010.

Quaas, J., Boucher, O., Bellouin, N., and Kinne, S.: Satellite-based estimate of the direct and indirect aerosol climate forcing, J. Geophys. Res., 113, D05204, doi:10.1029/2007JD008962, 2008.

Queface, A. J., Piketh, S. J., Annegarn, H. J., Holben, B. N., and Uthui, R. J.: Retrieval of aerosol optical thickness and size distribution from the CIMEL sun photometer over Inhaca island, Mozambique, J. Geophys. Res., 108, 8509, doi:10.1029/2002JD002374, 2003.

Reid, J. S., Koppmann, R., Eck, T. F., and Eleuterio, D. P.: A review of biomass burning emissions part II: intensive physical properties of biomass burning particles, Atmos. Chem. Phys., 5, 799825, doi:10.5194/acp-5-799-2005, 2005.

Remer, L. A., Tanré, D., Kaufman, Y., Levy, R., and Mattoo, S.: Algorithm for Remote Sensing of Tropospheric Aerosol from MODIS: Collection 005, Rev 2, 97 pp, available at: http: //modis-atmos.gsfc.nasa.gov, last access: 14 November 2009, February 2009.

Sekiguchi, M., Nakajima, T., Suzuki, K., Kawamoto, K., Higurashi, A., Rosenfeld, D., Sano, I., and Mukai, S.: A study of the direct and indirect effects of aerosols using global satellite data sets of aerosol and cloud parameters, J. Geophys. Res., 108, 4699, doi:10.1029/2002JD003359, 2003.

Smirnov, A., Holben, B. N., Kaufman, Y. J., Dubovik, O., Eck, T. F., Slutsker, I., Pietras, C., and Halthore, R. N.: Optical properties of atmospheric aerosol in maritime environments, J. Atmos. Sci., 59, 501-523, 2002.

Stephens, G., Vane, D. G., Boain, R. J., Mace, G. G., Sassen, K., Wang, Z., Illingworth, A. J., O'Connor, E. J., Rossow, W. B., Durden, S. L., Miller, S. D., Austin, R. T., Benedetti, A., and Mitrescu, C., and The CloudSat Science Team: The CloudSat mission and the A-Train, B. Am Meteorol. Soc., 83, 1771-1790, 2002.

Stephens, G. L.: Radiation Profiles in Extended Water Clouds - II: Parameterization Schemes, J. Atmos. Sci., 12, 2123-2132, 1978.

Stevens, B. and Feingold, G.: Untangling aerosol effects on clouds and precipitation in a buffered system, Nature, 461, 607-613, doi:10.1038/nature08281, 2009.

Swap, R. J., Annegarn, H. J., Suttles, J. T., King, M. D., Platnick, S., Privette, J. L., and Scholes, R. J.: Africa burning: A thematic analysis of the Southern African Regional Science Initiative (SAFARI 2000), J. Geophys. Res., 108, 8465, doi:10.1029/2003JD003747, 2003. 
Tanré, D., Kaufman, Y. J., Herman, M., and Mattoo, S.: Remote sensing of aerosol properties over oceans using the MODIS/EOS spectral radiances, J. Geophys. Res.-Atmos., 102, 16971-16988, 1997.

Thieuleux, F., Moulin, C., Bréon, F. M., Maignan, F., Poitou, J., and Tanré, D.: Remote sensing of aerosols over the oceans using MSG/SEVIRI imagery, Ann. Geophys., 23, 3561-3568, doi:10.5194/angeo-23-3561-2005, 2005.

Twohy, C. H., Petters, M. D., Snider, J. R., Stevens, B., Tahnk, W., Wetzel, M., Russell, L., and Burnet, F.: Evaluation of the aerosol indirect effect in marine stratocumulus clouds: Droplet number, size, liquid water path, and radiative impact, J. Geophys. Res., 110, D08203, doi:10.1029/2004JD005116, 2005.

Twomey, S.: Pollution and the planetary albedo, Atmos. Environ., 8, 1251-1256, 1974.

Twomey, S.: The influence of pollution on the shortwave albedo of clouds, J. Atmos. Sci., 34, 1149-1152, 1977.

Twomey, S.: An assessment of the impact of pollution on global cloud albedo, Tellus, Ser. B, 36, 356-366, 1984.

Varnai, T. and Marshak, A.: MODIS observations of enhanced clear sky reflectance near clouds, Geophys. Res. Lett. 36, L06807, doi:10.1029/2008GL037089, 2009.
Warner, J.: A reduction in rainfall associated with smoke from sugar-cane fires: an inadvertent weather modification, J. Appl. Meteorol., 7, 247-251, 1968.

Cahalan, R. F.: Importance of molecular Rayleigh scattering in the enhancement of clear sky reflectance in the vicinity of boundary layer cumulus clouds, J. Geophys. Res., 113, D24207, doi:10.1029/2008JD010592, 2008.

Wilcox, E. M., Harshvardhan, and Platnick, S.: Estimate of the impact of absorbing aerosol over cloud on the MODIS retrievals of cloud optical thickness and effective radius using two independent retrievals of liquid water path, J. Geophys. Res., 114, D05210, doi:10.1029/2008JD010589, 2009.

Winker, D. M., Hunt, W. H., and Hostetler, C. A.: Status and performance of the CALIOP lidar, Proc. SPIE Int. Soc. Opt. Eng., $5575,8-15,2004$.

Winker, D. M., Hunt, W. H., and McGill, M. J.: Initial performance assessment of CALIOP, Geophys. Res. Lett., 34, L19803, doi:10.1029/2007GL030135, 2007. 